1925R1 (Revision 1)

\title{
Structural model for the biogenic Mn oxide produced by Pseudomonas putida
}

\author{
Mario Villalobos ${ }^{1, *}$, Bruno Lanson ${ }^{2}$, Alain Manceau ${ }^{2}$, Brandy Toner $^{3}$, and Garrison Sposito ${ }^{3}$ \\ ${ }^{1}$ Environmental Bio-Geochemistry Group, LAFQA, Instituto de Geografía, National \\ Autonomous University of Mexico (UNAM), Circuito Exterior, Ciudad Universitaria, \\ México, Coyoacán, 04510, D.F., México \\ ${ }^{2}$ Environmental Geochemistry Group, LGIT, Maison des Géosciences, BP53, University of \\ Grenoble - CNRS, 38041 Grenoble Cedex 9, France \\ ${ }^{3}$ Division of Ecosystem Sciences, University of California at Berkeley, \\ Berkeley, CA 94720-3110, USA
}

\begin{abstract}
X-ray diffraction (XRD) and Mn K-edge extended X-ray absorption fine structure (EXAFS)

spectroscopy were combined to elaborate a structural model for phyllomanganates (layer-type Mn oxide) lacking 3D ordering (turbostratic stacking). These techniques were applied to a sample produced by a common soil and freshwater bacterium (Pseudomonas putida) and to
\end{abstract} two synthetic analogs, $\delta-\mathrm{MnO}_{2}$ and "acid birnessite", obtained by the reduction of potassium permanganate with $\mathrm{MnCl}_{2}$ and $\mathrm{HCl}$, respectively. To interpret the diffraction and spectroscopic data, we applied an XRD simulation technique utilized previously for wellcrystallized birnessite varieties, complementing this approach with single-scattering-path simulations of the Mn K-edge EXAFS spectra. Our structural analyses revealed that all three Mn oxides have an hexagonal layer symmetry with layers comprising edge-sharing $\mathrm{Mn}^{4+} \mathrm{O}_{6}$ octahedra and cation vacancies, but no layer $\mathrm{Mn}^{3+} \mathrm{O}_{6}$ octahedra. The proportion of cation vacancies in the layers ranged from 6 to $17 \%$, these vacancies being charge-compensated in the interlayer by protons, alkali metals, and Mn atoms, in amounts that vary with the phyllomanganate species and synthesis medium. Both vacancies and interlayer Mn were

*Author to whom correspondence should be addressed (marvilla@igiris.igeograf.unam.mx) 
most abundant in the biogenic oxide. The diffracting crystallites contained three to six randomly stacked layers, and have coherent scattering domains of $19-42 \AA$ in the $\mathbf{c}^{*}$ direction, and $60-85 \AA$ in the ab plane. Thus, the Mn oxides investigated here are nanoparticles that bear significant permanent structural charge resulting from cation layer vacancies and variable surface charge from unsaturated $\mathrm{O}$ atoms at layer edges.

\section{INTRODUCTION}

Manganese 2+ oxidation occurs primarily through biological mediation in the oxic and oxic/anoxic transition zone of aqueous environments (Tipping et al. 1984; Nealson et al. 1988; Tebo 1991; Ghiorse and Ehrlich 1992; Bartlett and James 1993; Wehrli et al. 1995; Tebo et al. 1997, Harvey and Fuller 1998; Tebo and He 1999; Marble et al. 1999; Morgan 2000; Kay et al. 2001). The oxidation products are mainly insoluble $\mathrm{Mn}^{4+}$ oxides of the birnessite family (i.e., hydrous phyllomanganates) comprising edge-sharing $\mathrm{Mn}-\mathrm{O}_{6}$ octahedra with high negative permanent structural charge, due principally to vacant cation layer sites, and correspondingly high cation sorption capacities (Chukhrov et al. 1985; Strobel et al. 1987; Drits et al. 1997; Silvester et al. 1997; Lanson et al. 2000; Bilinski et al. 2002).

Todorokite, a Mn oxide with tunnel structure, has also been found associated with birnessites in natural settings, but, since the latter are believed to be precursors to formation of the former (Golden et al. 1987; Shen et al. 1993; Tian et al. 1997; Ching et al. 1999; Luo et al. 1999; Feng et al. 2001), todorokite is probably not a direct product of microbial oxidation.

Natural Mn oxides often are poorly-crystalline solids (Tipping et al. 1984; Friedl et al. 1997; McKeown and Post 2001; Bilinski et al. 2002; Manceau et al. 2003, 2004) and rather few structural investigations of them have been performed (Chukhrov et al. 1985, 1989; Manceau 
et al. 1992; Gorshkov et al. 1992). Mineralogical techniques that rely on the presence of long-range order, such as X-ray and electron diffraction, have been applied mainly to synthetic analogs of natural birnessites, most often with an enhanced three-dimensional (3D) ordering (Holland and Walker 1996; Drits et al. 1997; Silvester et al. 1997; Lanson et al. 2000, 2002a; Post et al. 2002; Jurgensen et al. 2004). These techniques have revealed the presence of two-layer symmetries, orthogonal $(a>b \sqrt{3})$ as in triclinic Na-birnessite, and hexagonal $(a=b \sqrt{ } 3)$ as in H-birnessite, depending on the predominant origin of the layer charge $\left(\mathrm{Mn}^{3+}\right.$ for $\mathrm{Mn}^{4+}$ substitution, or vacant $\mathrm{Mn}^{4+}$ sites within the octahedral sheet, respectively). H-birnessite is formed under acidic $\mathrm{pH}$ conditions (Silvester et al. 1997). It has the hexagonal unit-cell parameters $a=4.940 \AA, b=a / \sqrt{ } 3=2.852 \AA, c=7.235 \AA, \alpha=\beta=$ $\gamma=90^{\circ}$, with $0.833 \mathrm{Mn}$ ions and 0.167 cation vacancies per layer octahedron, and 0.167 interlayer $\mathrm{Mn}^{3+}$ ions located above or below layer vacancies in a triple-corner sharing configuration. The vacancies are long-range ordered, in that they appear in every third row of Mn cations along [100], with half of the Mn sites along these rows being vacant (Drits et al. 1997). Water molecules associated with interlayer Mn cations provide for strong hydrogen bonds between the layers (Lanson et al. 2000).

Villalobos et al. (2003) characterized a set of analogs of natural birnessites showing a limited 3D ordering, including a biogenic Mn oxide produced in culture by a common soil and freshwater bacterium, Pseudomonas putida. Based on comparison of their layer symmetry, Mn oxidation numbers, and other physicochemical properties, all of the Mn oxides investigated appeared to be more structurally related to hexagonal H-birnessite than to the triclinic Na-birnessite variety. Also, the biogenic Mn oxide was concluded to have reactive and structural properties intermediate between those of the synthetic c-disordered phyllomanganates $\delta-\mathrm{MnO}_{2}$ and "acid birnessite", which are formed through the reduction of 

8 9

permanganate with $\mathrm{MnCl}_{2}$ or $\mathrm{HCl}$, respectively. More recently, Jurgensen et al. (2004) studied the structure of the Mn oxide produced by another bacterium species (Leptothrix discophora) by X-ray absorption fine structure (XAFS) spectroscopy and X-ray diffraction (XRD). They found that this compound consists of single octahedral-layer microcrystals composed of $\mathrm{Mn}^{4+}, \mathrm{Mn}^{3+}$, and $\mathrm{Mn}^{2+}$ similarly to triclinic Na-birnessite. They also identified the possible location of some Mn octahedra in corner-sharing configuration with those from the layer plane, as in H-birnessite.

The birnessite samples previously studied by Villalobos et al. (2003) appear to have simple layer structures made up almost entirely of $\mathrm{Mn}^{4+}$ octahedra, their complexity arising from the presence of layer vacancies and lack of 3D ordering. In the present paper, we extend our previous work with a detailed structural investigation of the same samples using quantitative XRD and extended XAFS (EXAFS) spectroscopy. To interpret the XRD data, we applied a simulation technique utilized previously for birnessites with an enhanced 3D ordering (Manceau et al. 1997; Drits et al. 1998a; Lanson et al. 2000, 2002a, b), complementing this approach with single-scattering-path analyses of Mn K-edge EXAFS spectra. (1)

\section{EXPERIMENTAL METHODS}

The biogenic Mn oxide and its two synthetic analogs were prepared using methods described in Villalobos et al. (2003). Briefly, the biogenic Mn oxide was produced in cultures of Pseudomonas putida strain MnB1 provided by Dr. B. M. Tebo (Scripps Institution of Oceanography). Bacteria were grown at $27^{\circ} \mathrm{C}$ to the stationary phase of growth in a liquid 
106 suspension rich in nutrients and in the presence (or absence, for a cell control sample) of total

$107\left(\mathrm{Mn}^{2+}\right)=1.0 \mathrm{mM}$. A sample of the biogenic oxide was cleaned of organic material by 108 gradual iterative oxidation using $0.2 \% \mathrm{NaOCl}$ reagent, taking care not to oxidize $\mathrm{Mn}^{4+}$ or

$109 \mathrm{Mn}^{3+}$ in the sample. $\delta-\mathrm{MnO}_{2}$ was prepared using a "redox" method with stoichiometric

110 amounts of $\mathrm{KMnO}_{4}$ and $\mathrm{MnCl}_{2}$ reagents (Catts and Langmuir 1986; Mandernack et al. 1995;

111 Luo and Suib 1997; Luo et al. 2000). Physicochemical characterization of the sample

112 (Villalobos et al. 2003) indicated a composition exclusively of $\mathrm{Mn}^{4+}$ and a highly $\mathrm{pH}-$

113 dependent cation sorption capacity. Acid birnessite was prepared by reducing $\mathrm{KMnO}_{4}$ with

114 concentrated $\mathrm{HCl}$ at boiling temperature (McKenzie 1971). The solids were oven-dried

115 overnight at $70{ }^{\circ} \mathrm{C}$, except for acid birnessite, which was freeze-dried, and a sample of

116 uncleaned biogenic oxide, which was washed, centrifuged, and left as a wet paste for in-situ

117 EXAFS spectroscopy.

119 Thermogravimetric analyses (TGA) were performed to determine the water content on ca. 20

$120 \mathrm{mg}$ of the dried samples except for the uncleaned biogenic oxide. The weight loss was

121 measured by heating the samples on a Pt tray from room temperature to ca. $250{ }^{\circ} \mathrm{C}$ at a rate

122 of $10^{\circ} \mathrm{C} / \mathrm{min}$ (SDT 2960 apparatus from TA Instruments). Alumina powder was used as

123 reference material for weight loss calibrations. Two peaks were obtained in plots of

124 weight/temperature differentials vs. temperature for all samples. They were decomposed

125 using Galactic Grams 32 (vol. 6) software to determine the fractions of loosely bound

126 (removed at $<80{ }^{\circ} \mathrm{C}$ ) and strongly sorbed water (retained up to $250{ }^{\circ} \mathrm{C}$ ), but excluding

127 structural water bound to interlayer Mn cations. Duplicate analyses per sample were

128 performed and the results obtained were used to constrain the water contents in the XRD

129 simulations. Results are listed in Table 1. 
134 Dry samples were crushed in an agate mortar, and powder XRD patterns $(\mathrm{CuK} \alpha$ radiation, $\lambda=$

$1351.5418 \AA$ A) were collected with a Bruker D5000 powder diffractometer equipped with a Kevex $136 \mathrm{Si}(\mathrm{Li})$ solid-state detector. Intensities were measured at $0.04^{\circ} 2 \theta$ intervals with 40 s counting 137 time per step.

138 Simulations of XRD patterns were performed following the trial-and-error procedure

139 developed by Drits and Tchoubar (1990) and applied previously to both natural and synthetic

140 birnessites (Chukhrov et al. 1985; Manceau et al. 1997; Drits et al. 1998a; Lanson et al. 2000,

141 2002a, 2002b). Details on the programs used to simulate XRD patterns and on the fitting

142 procedure are given by Drits and Tchoubar (1990), Drits et al. (1998a), and Plançon (2002).

143 As the main features of XRD profiles recorded for the three samples resemble those reported

144 by Drits et al. (1997) for turbostratic birnessite, the experimental patterns were divided for the

145 simulations in two angular domains containing different families of reflections. In the low-

146 angle region $\left(5-30^{\circ} 2 \theta \mathrm{CuK} \alpha-\mathrm{d}\right.$-spacing $>10$ to $\left.3.0 \AA\right), 00 l$ reflections were calculated to

147 assess the validity of the lamellar structure proposed by Villalobos et al. (2003) for the

148 synthetic oxides. In addition, the simulation of $00 l$ reflections allowed quantification of the

149 extent of coherent scattering domains (CSDs) along the axis perpendicular to the ab plane (c*

150 axis) using a lognormal distribution of CSD sizes parameterized by an average number of

151 layers $\left(\mathrm{N}_{\mathrm{Av}}-\right.$ Drits et al. 1998b). In the high-angle range $\left(32-75^{\circ} 2 \theta \mathrm{CuK} \alpha-d\right.$-spacing 2.80 -

$1521.27 \AA$ ), the $20 l, 11 l$ and the $02 l, 31 l$ reflections (Miller indexing based on a C-centered unit

153 cell) were calculated to determine the structure of both the octahedral layer and the interlayer

154 region (atomic coordinates and occupancies of the different sites). CSDs in the ab plane were

155 assumed to have a disk-like shape whose average radius was constrained by fitting the first of 
156 the two high-angle maxima. For all samples, the background was assumed to decrease

157 linearly over the angular range considered. The average Mn oxidation number along with the

158 alkali metal and structural water content of the samples were used to constrain initial

159 assumptions about the stoichiometry of interlayer species in the simulations. Quality of fit

160 was assessed over the $34-75^{\circ} 2 \theta \mathrm{CuK} \alpha$ range assuming the commonly employed $R_{W P}$ factor,

161 and comparing it to the statistical error associated with measured intensities $\left(R_{E x p}\right)$ (Howard

162 and Preston 1989).

163

164 EXAFS Spectroscopy

165

166 Manganese K-edge EXAFS spectra were measured at room temperature on wiggler beamline

$167 \quad 4-3$ at the Stanford Synchrotron Radiation Laboratory in transmission mode. A Si(220)

168 crystal pair was used to create monochromatic X-rays and a Pt-coated mirror was used to

169 reject harmonic X-rays. A 1-mm vertical entrance slit located $17.2 \mathrm{~m}$ from the source was

170 used to improve the energy resolution by reducing the beam divergence on the

171 monochromator. Dry Mn oxide samples were mixed with $\mathrm{LiCO}_{3}\left[\mathrm{Mn}\right.$ oxide: $\mathrm{LiCO}_{3}(\mathrm{w} / \mathrm{w})$

$172 \approx 1: 10]$, to ensure an absorbance of the edge jump of 1 to 1.5 , then mounted on 1 -mm thick

173 Teflon holders in $25 \mathrm{~mm} \times 3 \mathrm{~mm}$ slots. Raw biogenic oxide with cellular material was

174 centrifuged and mounted directly as wet paste into these holders. Samples were held in place

175 with Kapton tape X-ray windows. Spectra were acquired over the energy range 6400 to 7400

$176 \mathrm{eV}$, with typically two to three runs per sample performed, each run taking approximately 30

177 min. Either a permanganate solid $\left(\mathrm{Mn}^{7+}\right)$ (absorption edge jump at $6543 \mathrm{eV}$ set at the

178 maximum of the first derivative of the edge) or a Mn metal foil (absorption edge jump at

$1796539 \mathrm{eV})$ were used to calibrate the monochromator before every sample run. No beam-

180 induced changes in Mn oxidation state were observed. 
182 The EXAFS data analysis was performed in the single-scattering approximation using home183 made software for data normalization and Fourier transformation, and WinXAS (Ressler 184 1998) for spectral simulations. Fourier transformations were done on the entire $\mathrm{k}^{3} \chi(\mathrm{k})$ curves 185 shown in the Results section with a Kaiser-Bessel window $(\tau=3)$. Transformation from 186 reciprocal $(k)$ to real $(\mathrm{R})$ space produces radial structure functions (RSFs) with peaks corresponding to average absorber-backscatterer distances, but deviating from the true $\mathrm{R}$

188 distance by $\Delta \mathrm{R}$ due to a phase shift. Spectral simulations were performed on Fourier-filtered data using Mn-O and Mn-Mn phase shift and amplitude functions calculated with FEFF v. 7 (Zabinsky et al. 1995) for the $\lambda-\mathrm{MnO}_{2}$ reference (Thackeray et al. 1993). The Mn-O and Mn-

191 Mn Feff files were tested on the spectrum of the reference, and good agreement was found between EXAFS and crystallographic values. $\Delta E$, the difference between the experimental

193 (taken to be the half-edge jump point) and theoretical origins for the energy scale (E), was

194 treated as a single adjustable parameter for all sets of backscattering atoms, and $S_{0}^{2}$, the

195 amplitude reduction factor, was calibrated using $\lambda-\mathrm{MnO}_{2}$. Since the EXAFS analysis in the 196 present work is limited to single-scattering-path calculations, any interpretation of long

197 distance Mn-Mn pairs shells $(\mathrm{R}+\Delta \mathrm{R}>3.5 \AA)$, which requires full multiple-scattering 198 calculations, is semi-quantitative. Below this distance, multiple scattering (MS) contributions 199 are negligible (see Figure 15 of Manceau et al. 1998).

\section{RESULTS AND DISCUSSION}

\section{XRD Patterns}

204 Figure 1 shows a maximum of four major XRD peaks for the Mn oxide samples studied, 205 whose positions and relative intensities closely resemble those reported by Drits et al. (1997) 
for turbostratic birnessite. From this positive comparison it is possible to hypothesize that the

207 two peaks occurring at $\sim 7.3-8.0 \AA$ and 3.6-3.8 $\AA$ correspond to 001 and 002 basal reflections, 208 although they do not strictly define a rational series. In addition, these reflections are 209 significantly shifted as compared to the positions of 001 reflections commonly reported for birnessite samples. The two peaks observed at higher angles $(2.42-2.44$ and $1.41-1.42 \AA)$

211 likely correspond to 20,11, and 02,31 bands, respectively, choosing a C-centered layer cell.

212 The ratio of the $d$ values of the two bands $(1.720-1.725)$ is close to the $1.732=\sqrt{ } 3$ value 213 expected for layers having a hexagonal symmetry. These bands do not show significant 214 modulations of the $h k l$ reflections and instead exhibit a strong asymmetry on their high-angle 215 side. This profile shape is characteristic of lamellar compounds with a turbostratic stacking, 216 i.e., lacking well-defined displacement/rotation between successive layers (Brindley and 217 Brown 1980). A broad "hump" is however visible at ca. 50-55 ${ }^{\circ} 2 \theta \mathrm{CuK} \alpha$ for all three 218 samples (Figure 1). In comparison to the acid-birnessite (Fig. 1a), the first two maxima at $\sim 8$ 219 and $3.8 \AA$ for $\delta-\mathrm{MnO}_{2}$ are broadened (Fig. 1b), and also significantly shifted relative to their 220 ideal positions for a "7 $\AA$ " lamellar compound. The broadening of the basal reflections of $\delta$ $221 \mathrm{MnO}_{2}$ extends to the 20,11 and 02,31 bands, and the broad "hump" between 50 and $55^{\circ} 2 \theta$ $222 \mathrm{CuK} \alpha$ has a different shape from that of the acid birnessite pattern. The two low-angle 223 maxima of the pattern for the biogenic oxide are at $\sim 7.6$ and $3.8 \AA$, and have a shape 224 intermediate between those of the two previous samples (Fig. 1c). The biogenic oxide pattern 225 exhibits an additional shoulder on the low-angle side of the $3.8 \AA$ maximum. This shoulder 226 arises from the contribution of dead cells to the diffracted intensity, as shown on the XRD 227 pattern from the bacteria alone (Fig. 1d). The admixture of bacterial cells does not modify 228 significantly the pattern from the biogenic oxide component in the high-angle region. The 229 two 20,11 and 02,31 bands are still observed for the biogenic oxide, but the high-angle tail of 
230 the former is less pronounced than in the two other samples, and the hump is slightly shifted 231 to higher $2 \theta$ values.

\section{Simulations of the Low-Angle Region (5-30²0 CuK $\alpha)$}

One objective of these simulations was to verify if the observed non-rationality and the significant positional shift of the two diffraction maxima observed in this low-angle range was related to the small dimensions of the CSDs along the $\mathbf{c}^{*}$ direction as described by Drits and Tchoubar (1990) for layer silicates. Calculations were performed assuming a lamellar structure for all three oxides considered. Elementary birnessite layers consist of the sheet of Mn octahedra itself, which possibly contains vacant layer sites, and of associated interlayer species, which include interlayer $\mathrm{Mn}$ and alkali cations and coordinated $\mathrm{H}_{2} \mathrm{O}$ molecules (see

243 determined from the analysis of $h k l$ bands. Upon fixing these values, the amplitude, width, 244 and position of the experimental diffraction peaks in this region essentially depend on the size 245 of the CSDs along $\mathbf{c}^{*}$ and, therefore, on the number of layers in the diffracting crystallites.

246 Although the fits to the experimental data are not perfect, the main features of the diffraction 247 patterns were fairly reproduced by the simulations (Fig. 2). In particular, for all three samples 248 the calculated positions, widths, and relative intensities were similar to the experimental data, 249 thus providing strong support for the assumed lamellar structure of the unknowns (Villalobos et al. 2003). For the biogenic sample, the scattering from dead bacterial cells was not

251 included in the calculation and, hence, only the high-angle contribution of the 002 peak was 252 reproduced. The average sizes of the CSDs estimated from the models equal 2.6 layers $(\sim 1.9$ $253 \mathrm{~nm})$ for $\delta-\mathrm{MnO}_{2}, 2.8$ layers $(\sim 2.0 \mathrm{~nm})$ for the biogenic oxide, and 5.8 layers $(\sim 4.2 \mathrm{~nm})$ for the acid birnessite (Table 2). 


\section{Simulations of the high-angle region $\left(>30^{\circ} 2 \theta \mathrm{CuK} \alpha\right)$}

The successful simulation of the low-angle peaks supports our indexing of the high-angle reflections as 20,11 and 02,31 bands. As compared to equivalent reflections for hydrous layer silicates (Manceau et al. 2000a,b), the profiles of the 20,11 reflections are modulated and their shapes are different from one sample to another, indicating a variation of the structure factors, and hence of the sample structures. As will be shown below, these modulations can be used to determine both the layer and interlayer structures of the phyllomanganate samples despite the absence of any 3D ordering. For all simulations the generic structural formula,

$$
\mathrm{H}_{\mathrm{a}}(\mathrm{Na}, \mathrm{K})_{\mathrm{b}} \mathrm{H}_{2} \mathrm{O}_{\mathrm{c}} \mathrm{Mn}^{3+, 2+}{ }_{t c}\left[\mathrm{Mn}^{4+}{ }_{\mathrm{d}}, \mathrm{Vac}_{\mathrm{e}}\right] \mathrm{O}_{2}
$$

was assumed, where interlayer species are written to the left of the square brackets and tc refers to interlayer $\mathrm{Mn}$ in triple corner-sharing positions above or below cation vacancies 271 (vac) in the layer (enclosed in square brackets, except for the oxygens). The stoichiometric coefficients were calculated from the average Mn oxidation number and the alkali metal content determined previously (Villalobos et al. 2003), and from the water content determined by TGA (Table 1). Parameters refined in the XRD simulations include the unitcell dimensions in the ab plane, from the position of the two high-angle maxima, and the amount of vacant layer sites, the amount and position of interlayer Mn cations, the positions of interlayer alkali cations and of associated $\mathrm{H}_{2} \mathrm{O}$ molecules, and the size of the CSDs in the ab plane. All sample spectra were simulated assuming an hexagonal layer symmetry and choosing a C-centered unit-cell with parameters $b=2.838 \AA, a=b \sqrt{3}=4.916 \AA, \gamma=90^{\circ}$, and 
a basal $d(001)$ distance of $7.20 \AA$. No parameters were used to define the layer-stacking

281 mode, as layer stacking is random with $\mathrm{W}_{\mathrm{R}}$, the occurrence probability of random

282 displacement/rotation between adjacent layers, being equal to $100 \%$. Optimal parameters

283 obtained from the simulations are listed in Tables 2 and 3, and selected interatomic distances

284 are reported in Table 4.

285

$286 \delta-\mathbf{M n O}_{2}$. Since the average Mn oxidation number measured for this oxide is 4.0 (Table 1),

287 the layer charge deficit was assumed to arise only from vacant layer sites. The optimal model

288 had $6 \%$ octahedral vacancies and did not contain interlayer Mn (tc $=0)$. Accordingly, the

289 layer charge deficit was compensated by interlayer $\mathrm{Na}$, whose fraction was constrained to be

290 four times the refined fraction of vacant layer sites. The amount of interlayer $\mathrm{H}_{2} \mathrm{O}$ was

291 assumed to be three times the amount of interlayer $\mathrm{Na}$ (Post and Veblen 1990), leading to a

292 water content (12.7\%) consistent with the TGA value (15.8\%), although somewhat smaller.

293 Thus, the structural formula corresponding to the optimum fit shown in Figure $3 \mathrm{a}\left(\mathrm{R}_{\mathrm{WP}}=10.7\right.$

$\left.294 \%, \mathrm{R}_{\mathrm{EXP}}=3.5 \%\right)$ is:

$$
\mathrm{Na}_{0.24}\left(\mathrm{H}_{2} \mathrm{O}\right)_{0.72}\left[\mathrm{Mn}^{4+}{ }_{0.94}, \mathrm{vac}_{0.06}\right] \mathrm{O}_{2}
$$

298 The coordinates of $\mathrm{Na}$ and $\mathrm{H}_{2} \mathrm{O}$ are $(0.225,0,1 / 2)$ (Table $3 \mathrm{a}-$ Fig. 4) and the distance

299 between water molecules and nearest layer oxygen atoms $\left(\mathrm{O}_{\text {layer }}\right)$ is $2.65 \AA$, which is

300 favorable to the formation of strong H-bonds (Table 4).

302 Acid Birnessite. The average Mn oxidation state of slightly lower than 4.0 (Table 1)

303 suggests the occurrence of $\mathrm{Mn}^{3+}$ cations, most likely above/below vacant layer sites, since the 304 layer has an hexagonal symmetry. Thus, the amounts and positions of interlayer Mn were 
optimized during the simulations, together with the amount of octahedral vacancies. The

306 amount of interlayer $\mathrm{H}_{2} \mathrm{O}$ was linked to that of alkali cations, as for the $\delta-\mathrm{MnO}_{2}$ simulation, and their positions were also optimized. The refined structural formula, which yielded the optimum match between the calculated scattering profile and data shown in Figure $3 b\left(R_{W P}=\right.$ $\left.9.3 \%, \mathrm{R}_{\mathrm{EXP}}=2.8 \%\right)$, is:

This sample has a higher amount of vacant layer sites ( 0.12 per octahedron) than $\delta-\mathrm{MnO}_{2}$, and only two-thirds of the octahedral vacancies ( 0.08 per octahedron) are capped on one side by octahedrally coordinated interlayer $\mathrm{Mn}^{3+}$ cations (Fig. 4). The stoichiometric coefficient of $\mathrm{Mn}^{3+}$ is about half that of H-birnessite (Lanson et al. 2000). The average Mn oxidation degree (3.92) determined by XRD agrees fairly well with the value determined by wet chemistry (3.96 \pm 0.02 - Villalobos et al. 2003), which provides confidence in the overall consistency of our structural approach. The remaining layer charge is balanced by interlayer $\mathrm{K}^{+}$cations and protons ( 0.18 and 0.06 per octahedron, respectively), the alkali metal content $(\mathrm{K} / \mathrm{Mn}=0.19)$ being consistent with the $\mathrm{K} / \mathrm{Mn}$ molar ratio measured by wet chemistry $(0.20$ \pm 0.008 - Villalobos et al. 2003). The amount of structural water $(9.6 \%)$ is consistent with the TGA value (7.5\% - Table 1), although somewhat larger. The position of the water molecules $(0.200,0.0,0.5-$ Table $3 b)$ is close to that determined for $\delta-\mathrm{MnO}_{2}(0.225,0.0$, 0.5 ), and again leads to a short $<\mathrm{H}_{2} \mathrm{O}-\mathrm{O}_{\text {layer }}>$ distance $(2.68 \AA$ ) that is favorable to the formation of strong $\mathrm{H}$-bonds with $\mathrm{O}_{\text {layer }}$. However, the assumption of a common position for $\mathrm{K}^{+}$and $\mathrm{H}_{2} \mathrm{O}$ did not yield optimal fits to the XRD pattern $\left(\mathrm{R}_{\mathrm{wp}}=10.3 \%\right)$. Best agreement between calculation and experiment was obtained with $\mathrm{K}^{+}$at $(-0.203,0.0,0.5)$, which is above or below empty tridentate cavities of the layer surface at $2.97 \AA$ from $\mathrm{O}_{\text {layer. }} \mathrm{K}$ atoms are 
slightly shifted in the ab plane from the center of the cavity in the direction of the nearest $\mathrm{O}_{\text {layer }}-\mathrm{O}_{\text {layer }}$ edge of the Mn layer (Fig. 4). This position is close to that refined by Gaillot et al. $(2003)(-0.229,0.0,0.5)$ for a birnessite single crystal having $11 \%$ octahedral vacancies, of which two thirds were capped on one side by $\mathrm{Mn}^{3+}$ cations. The similar layer and interlayer structures found in the disordered birnessite synthesized at room temperature and in the single crystal form synthesized at $800^{\circ} \mathrm{C}$ suggest common structural principles despite the differing conditions of formation of the two species.

Biogenic Oxide.

As noted above, X-ray scattering from bacterial cells does not produce any significant modulations of the diffracted intensity over the analyzed angular range (Fig. 1d) and, consequently, all experimental features were interpreted as arising from the manganate

342 admixture. As compared to the two previous samples, this oxide has an even lower Mn oxidation state $(3.90 \pm 0.05$ - Table 1$)$, thus suggesting a higher content of interlayer $\mathrm{Mn}$, and possibly also of octahedral vacancies. Also, this sample has a lower alkali/Mn ratio $(0.167$ \pm 0.003 ), which suggests a higher proportion of vacant layer sites capped by interlayer Mn. Accordingly, the optimum fit to the XRD pattern of this oxide (Fig. $3 c-R_{\mathrm{WP}}=9.8 \%, \mathrm{R}_{\mathrm{EXP}}=$ $3.1 \%$ ) was obtained for the following structural formula:

$$
\mathrm{H}_{\mathrm{a}} \mathrm{Na}_{0.15}\left(\mathrm{H}_{2} \mathrm{O}\right)_{0.45} \mathrm{Mn}^{2+, 3+}{ }_{0.167}\left(\mathrm{H}_{2} \mathrm{O}\right)_{0.50}\left[\mathrm{Mn}^{4+}{ }_{0.833}, \mathrm{vac}_{0.167}\right] \mathrm{O}_{2}
$$

The amounts of vacancies and interlayer Mn are identical ( 0.167 per octahedron), and the same as in H-birnessite (Lanson et al. 2000). However, the short $<\mathrm{Mn}-\mathrm{O}_{\text {layer }}>$ distance (1.92

$353 \AA$ - Table 4) pleads for the sole presence of $\mathrm{Mn}^{4+}$ within the octahedral layers in contrast to H-birnessite. In the optimized structural model, octahedrally coordinated interlayer Mn 
atoms are slightly farther from the layer surface $(z$-coordinate $=2.15 \AA-$ Table $3 \mathrm{c})$ than in

356 the other birnessite samples, including H-birnessite (z-coordinate $=2.10 \AA-$ Tables $3 \mathrm{a}, \mathrm{b}-$

357 Lanson et al. 2000). This position results in a $<\mathrm{Mn}_{\text {interlayer }}-\mathrm{O}_{\text {layer }}>$ distance of $2.00 \AA$, that is

358 significantly longer than usual (1.98 $\AA$ ). This increase in distance is consistent with the likely

359 presence of interlayer divalent Mn cations in the biogenic oxide. The residual layer charge is

360 balanced by interlayer $\mathrm{Na}^{+}$cations ( 0.15 per octahedron) and protons, the amount of which

361 depends on the actual valency of interlayer Mn cations. The amount of interlayer $\mathrm{Na}$

estimated from our XRD model is consistent with the $\mathrm{Na} / \mathrm{Mn}$ molar ratio $(0.167 \pm 0.003)$

363 reported by Villalobos et al. (2003), and the amount of water bound to $\mathrm{Na}(8.2 \%)$ is slightly smaller than the TGA value (10.0\%). Finally, the optimized atomic coordinates for $\mathrm{Na}$ and

$\mathrm{H}_{2} \mathrm{O}$ are similar to those obtained for $\delta-\mathrm{MnO}_{2}$, leading again to meaningful $<\mathrm{H}_{2} \mathrm{O}-\mathrm{O}_{\text {layer }}>$ and $<\mathrm{Na}-\mathrm{O}_{\text {layer }}>$ distances.

Sensitivity of Calculated XRD Patterns to Structural Parameters. As the optimum fits to the experimental data were obtained using a trial-and-error approach (making the assessment of uncertainties very difficult), the actual sensitivity of the XRD simulations to key structural parameters needs to be assessed. The sensitivity to the position of interlayer species will be illustrated by taking $\delta-\mathrm{MnO}_{2}$ as a case study. The optimum positions of $\mathrm{Na}$ and $\mathrm{H}_{2} \mathrm{O}[(0.225$, $0.0,0.5)$ and equivalent positions] are labeled "O3" in Figure 4 . Placing the two interlayer species above or below an empty layer octahedron [position $(0.0,0.0,0.5)$ - Alt. 1 in Fig. 4] modified the XRD profile considerably, especially the 20,11 band (Fig. $5 \mathrm{a}-\mathrm{R}_{\mathrm{WP}}=21.9 \%$ ).

376 Even a small shift of these "light" species from their optimum $(0.225,0.0,0.5)$ position to $377(0.333,0.0,0.5)$ (position “Alt. 2 " in Fig. 4) changed significantly the calculated XRD profile 378 relative to the best simulation (Fig. $5 b-R_{W P}=12.2 \%$ ). Finally, when interlayer species are 379 sitting above/below the tridentate cavities [Position "Alt. 3" in Fig. 4 with coordinates (- 
$0.167,0.0,0.5)]$, the calculated 20,11 band was broadened and differed greatly from

381 experimental data (Fig. $5 \mathrm{c}-\mathrm{R}_{\mathrm{WP}}=24.1 \%$ ).

382 Figure 6 illustrates the sensitivity of the calculated XRD profiles to the mean radial

383 dimension of the CSDs in the ab plane, taking again $\delta-\mathrm{MnO}_{2}$ as an example. In Figure 6a,

384 this dimension has been increased from $6.0 \mathrm{~nm}$, the optimum value (Table 2), to $10.0 \mathrm{~nm}$. As

385 a result, the 20,11 band peaks at lower $2 \theta$ value. In addition, the calculated band is sharper,

386 leading to a poorer reproduction of the experimental profile $\left(\mathrm{R}_{\mathrm{WP}}=15.0 \%\right)$. An opposite

387 effect is observed when the mean CSD radial dimension is decreased from 6.0 to $3.0 \mathrm{~nm}$ (Fig.

$\left.3886 \mathrm{~b}-R_{\mathrm{WP}}=11.6 \%\right)$. Note that the CSD size does not affect the position of the modulation at

389 about $45^{\circ} 2 \theta \mathrm{CuK} \alpha$, which depends only on the layer structure.

391 The sensitivity of the calculated XRD profiles to the location and amount of interlayer Mn is

392 illustrated next with the biogenic oxide (Fig. 7). Decreasing the stoichiometric coefficient tc

393 (Equation 1) from its optimum 0.167 value to 0.100 modified the shape of the high-angle

394 "tail" of the 20,11 band in a manner that smoothened the scattering dip at $\sim 45^{\circ} 2 \theta \mathrm{CuK} \alpha$

395 rendering the calculated hump less pronounced (Fig. $7 \mathrm{a}-R_{\mathrm{WP}}=11.3 \%$ ) relative to the

396 optimum fit (Fig. $3 \mathrm{c}-R_{\mathrm{WP}}=9.8 \%$ ). When both the proportion of interlayer Mn and layer

397 vacancies were decreased from 0.167 to 0.100 , the lineshape of the 20,11 band was

398 broadened (Fig. $7 \mathrm{~b}-\mathrm{R}_{\mathrm{WP}}=14.6 \%$ ). As expected from the high sensitivity of the calculated

399 XRD patterns to the position of "light" interlayer species, demonstrated previously with $\mathrm{Na}$

400 and $\mathrm{H}_{2} \mathrm{O}$ in $\delta-\mathrm{MnO}_{2}$, moving interlayer $\mathrm{Mn}$ from its optimal position dramatically modified

401 the 20,11 lineshape, as observed when the 0.167 interlayer Mn atoms were located

402 above/below the tridentate cavities (position Alt. 3 - Fig. 4; Fig. 7c $-\mathrm{R}_{\mathrm{wP}}=25.3 \%$ ). 


\section{EXAFS Spectra}

405

406 The $\mathrm{k}^{3}$-weighted Mn K-edge EXAFS spectra collected for the samples are shown in Figure

407 8a. Frequencies for all the Mn oxides studied were similar, with differences between the 408 samples arising mostly in the amplitudes. These amplitude differences are also evident in the 409 corresponding radial structure functions (RSFs, uncorrected for phase shifts) shown in Figure 4108 b. The uncleaned biogenic oxide sample shows a somewhat distinctive behavior at low $k$ 411 values (Fig. 8a). These effects are probably a contribution of a relatively important $\mathrm{Mn}^{2+}$ 412 fraction (16-19 mole \%) in this sample, which is absent from the others (Villalobos et al. 413 2003).

The RSFs exhibit two principal peaks at similar interatomic distances for all samples (Fig.

$4168 \mathrm{~b}$ ), including the uncleaned biogenic oxide. From a qualitative comparison with previously417 reported spectra for layer type Mn oxides, it can be concluded that these two peaks arise 418 mainly from single-scattering photoelectron interactions in the first $\mathrm{Mn}-\mathrm{O}$ shell and in the 419 second Mn-Mn shell, respectively (Manceau and Combes 1988; Manceau et al. 1992b; 420 Silvester et al. 1997). Differences among the samples are observed mostly in the peak 421 amplitudes, particularly for the Mn-Mn peak, and in the small feature that appears just 422 beyond this peak at ca. $\mathrm{R}+\Delta \mathrm{R}$ of $3 \AA$. This feature was used to elucidate important structural 423 differences between the Mn oxides using single-scattering ab initio FEFF simulations.

424 Specifically, the presence of a shoulder or a distinctive peak at $\mathrm{R}+\Delta \mathrm{R} \sim 3 \AA$ for the uncleaned 425 biogenic oxide may be indicative of Mn octahedra in different configurations from the edge426 sharing octahedra in the layers, e.g. triple-corner (TC) sharing octahedra, as observed in H427 birnessite and chalcophanite (Silvester et al. 1997) and in tectomanganates (Manceau and 428 Combes 1988). 
430 The EXAFS spectrum of the clean biogenic oxide clearly shows a shift in the $\chi(k)$ frequencies 431 in the region between 6 and $8 \AA^{-1}$ (Fig. 8a.), which manifests itself in the disappearance of the 432 feature at $\mathrm{R}+\Delta \mathrm{R} \sim 3 \AA$ in real space (Fig. 8b). This spectral feature is very similar to that seen 433 in the spectra of $\delta-\mathrm{MnO}_{2}$ (Fig. 9) and acid birnessite (Fig. 10). In contrast, the spectrum for 434 the unclean biogenic sample shows a strong similarity to that for H-birnessite, especially in 435 the region between 6 and $7 \AA^{-1}$ (Fig. 11a) and at $\mathrm{R}+\Delta \mathrm{R} \sim 3 \AA$ (Fig. 11b - feature C). Therefore, qualitatively, one may conclude that the biogenic sample as it is synthesized by the bacteria most likely contains interlayer Mn, in similar configuration to H-birnessite.

The peak caused by the third Mn layer shell at $\mathrm{R}+\Delta \mathrm{R} \sim 5.2 \AA$ (Fig. $11 \mathrm{~b}$, feature $\mathrm{D}$ ) is more

440 intense than the peak of the second Mn layer shell at $\mathrm{R}+\Delta \mathrm{R} \sim 4.5 \AA$, although the two shells 441 comprise six Mn atoms. The magnification of peak D has been attributed to a "focusing 442 effect" between aligned cations in layer type metal oxides (O'Day et al. 1994).

\section{Simulations of the EXAFS Spectra}

$\delta-\mathbf{M n O}_{2}$. This layer Mn oxide appears to have a simple structure (Fig. 8) arising from the homogeneity of its Mn oxidation state (Villalobos et al. 2003). The FEFF simulations of the $k^{3} \chi(k)$ data filtered in the $1.0<\mathrm{R}+\Delta \mathrm{R}<3.1 \AA$ interval are shown in Figure $12 \mathrm{a}$ and the

449 corresponding optimized parameters are listed in Table 5. The first two shells correspond to 450 Mn-O and Mn-Mn distances of $1.90 \AA$ and $2.87 \AA$, respectively. The edge-sharing 451 configuration of the $\mathrm{Mn}^{4+}$ octahedra (six shared edges per octahedron) is isostructural with 452 that in bivalent metal hydroxides of the brucite $\left[\mathrm{Mg}(\mathrm{OH})_{2}\right]$ group, including pyrochroite $453\left[\mathrm{Mn}(\mathrm{OH})_{2}\right]$. To reconcile the interatomic distances obtained by FEFF simulation with this 
454 configuration in a crystallographic model, the $\mathrm{Mn}^{4+}$ octahedra must flatten slightly. To 455 ensure a Mn-Mn distance of $2.87 \AA$ A between adjacent octahedra while keeping all Mn-O 456 distances equal to $1.90 \AA$, the O-O distance along shared edges must shorten to $2.49 \AA$ (Fig. 457 13, inset). The O-O distances along the unshared edges in this configuration are effectively 458 equal to the interatomic Mn-Mn distance of $2.87 \AA$.

460 An idealized octahedral sheet for $\delta-\mathrm{MnO}_{2}$ may now be constructed (Fig. 13) in which all Mn 461 near neighbor distances are determined by geometry alone. For example, a second $\mathrm{O}$ shell $462[\mathrm{O}(2)]$ is expected at $3.45 \AA$, and further Mn layer shells are expected at $4.97 \AA$ (dotted lines 463 in Fig. 13) and $5.74 \AA$. The $\mathrm{O}(2)$ shell at $3.45 \AA$ from Mn is within the range of influence of 464 the edge-sharing $\mathrm{Mn}$ shell [Mn(1)], and of the triple-corner sharing $\mathrm{Mn}$ shell [Mn(tc)], when 465 present, and, consequently, it was included in the spectral fits for all sample spectra.

466 However, spectral simulations showed that adding the $\mathrm{Mn}-\mathrm{O}(2)$ electronic wave improves the 467 fit in the 4-6 $\AA^{-1} k$ interval but does not modify significantly the EXAFS parameters from the $468 \mathrm{Mn}(1)$ and $\mathrm{Mn}(\mathrm{tc})$ shells because these shells have a maximum amplitude at higher $k$ 469 (Manceau and Combes 1988; Schlegel et al. 2001).

471 According to the ideal hexagonal layer model of $\delta-\mathrm{MnO}_{2}$, and in the absence of 472 configurations other than edge-sharing octahedra, six near neighbors of Mn centers are 473 expected for all shells (Fig. 13). The optimized fit for the $\mathrm{O}(1)$ shell indeed yielded $N$ very 474 close to 6 (Table 5). However, the $\mathrm{Mn}(1)$ shell fit produced a considerably lower value of $N$, 475 even when taking into account the commonly accepted precision of $20 \%$ in this parameter. 476 Two factors may predominate in causing this reduction: vacant cation sites (i.e., the absence 477 of some Mn near neighbors per Mn center present) and the contribution of particle-edge 
478 octahedra that have an incomplete shell of near neighbors, a contribution that is important

479 because of the small size of the layers in our samples.

480

481 Based on a Mn-Mn(1) distance of $2.87 \AA$ as obtained from analysis of the first Mn shell

482 (Table 5), and on a layer size estimate from our XRD simulations of $\delta-\mathrm{MnO}_{2}$ (from the

483 coherent scattering domain radial dimensions - Table 2), a rough estimate of the contribution

484 of layer-edge octahedra may be performed: one sheet of a square particle of dimensions $85 \times$

$48585 \AA^{2}$ yields a total of $(85 / 2.87)^{2}=900$ octahedra, of which $4 \times(85 / 2.87)=120$ occur at the

486 edges. The latter represents $13 \%$ of the total. Assuming smooth edges, we estimate that ca.

4874 Mn near-neighbors occur for every edge octahedron (Fig. 13). Thus the average number of

488 nearest Mn neighbors for all Mn atom centers in the $85 \times 85 \AA^{2}$ particle is about $0.13 \times 4+$

$489(1-0.13) \times 6=5.74$; i.e., a reduction of less than $5 \%$ from the ideal value. Therefore, the low

490 coordination number (28\% difference) observed by EXAFS spectral fitting must be due

491 primarily to the presence of vacant Mn sites. Unfortunately, the uncertainty of the predicted

$492 N$ value by EXAFS is too high to render a useful quantitative estimate of the vacancy content

493 by this method. However, it provides a convincing qualitative explanation for the occurrence

494 of $\mathrm{Mn} N$ values significantly lower than the theoretical value of 6 (Fig. 13).

495

496 Hexagonal birnessite with an Enhanced 3D Ordering. The H-birnessite (HBi) studied by

497 Silvester et al. (1997) has a more complex structure than $\delta-\mathrm{MnO}_{2}$ because of the presence of

498 significant $\mathrm{Mn}^{3+}$ in the layer and at interlayer sites in TC octahedra above cation vacancies.

499 The significant increase by $0.01 \AA$ of the $\mathrm{Mn}-\mathrm{Mn}(1)$ distance relative to $\delta-\mathrm{MnO}_{2}$ (Table 5) is

500 indicative of the presence of $\mathrm{Mn}^{3+}$ in the layer, whereas the Mn shell at $3.49 \AA$ with an

501 effective coordination number of 2.8 is characteristic of corner-sharing linkages between

502 layer and interlayer octahedra. 
504 Acid Birnessite. As expected from the average Mn oxidation number of 3.96 for this oxide

505 (Villalobos et al. 2003) and from the RSF (Fig. 8b) and XRD data, FEFF simulations gave

506 optimized structural parameters very similar to those for $\delta-\mathrm{MnO}_{2}$ (Fig. 12b, Table 5). The

507 main difference between the two structures lies in the larger size of the diffracting crystallites

508 (CSD) in acid birnessite.

509

510 Biogenic Oxide. Simulation of the NaOCl-cleaned sample of the biogenic oxide produced

511 shells and optimized structural parameters different from the uncleaned sample (Fig. 14), but

512 very similar to those of $\delta-\mathrm{MnO}_{2}$ and acid birnessite (Figs. 9, 10, 12c, Table 5). Figures $11 \mathrm{a}$

513 and 15a show that HBi has a higher wave frequency than the biogenic oxide, which translates

514 in real space to a shift to higher $\mathrm{R}+\Delta \mathrm{R}$ values of peaks B and D (Fig. 11b). Accordingly,

515 Table 5 shows that the Mn-Mn(1) distance is greater by $0.02 \AA$ in HBi. This is due to the

516 presence of layer $\mathrm{Mn}^{3+}$ in the latter, and its absence in the biogenic oxide. Matching the

517 simulation of HBi (Fig. 15b), the prominent shoulder at ca. $3 \AA$ in the RSF of the uncleaned

518 sample (peak C in Fig. 11b) was successfully simulated with a TC Mn shell at $3.49 \AA$ (Fig.

519 15c, Table 5). The oxidation state of this interlayer Mn species is different in the biogenic

520 oxide $\left[\mathrm{Mn}^{2+}\right]$ from that in $\mathrm{HBi}\left[\mathrm{Mn}^{3+}\right]$, however, the Mn-Mn(tc) EXAFS distance is the same

521 for both (Table 5). This may be explained as a trade-off between the larger radius of $\mathrm{Mn}^{2+}$

522 compared to $\mathrm{Mn}^{3+}$, and the need for $\mathrm{Mn}^{2+}$ to approach the layer at a closer distance to

523 compensate for a similar negative layer charge. This type of behavior has been reported in

524 chalcophanite, in which $\mathrm{Zn}$ is octahedrally-coordinated but has $\mathrm{Zn}-\mathrm{O}_{\text {layer }}$ distances

525 characteristic of a tetrahedral coordination owing to the lowering of the $\mathrm{Zn}$ position in the

526 direction of the layer (Wadsley 1955). 
Additionally, note that $N$ predicted for the $\mathrm{O}(1)$ shell of both is lower than for the other samples (Table 5). This difference occurs because the high proportion of low-valent $\mathrm{Mn}$ in the sample causes a higher disorder in the Mn-O EXAFS frequency, manifested in a decrease from what would be observed for pure $\mathrm{Mn}^{4+}-\mathrm{O}$ pairs. This situation is illustrated in Figure 16, which shows an EXAFS simulation for a hypothetical system consisting of $80 \% \mathrm{Mn}^{4+}-\mathrm{O}$ and $20 \% \mathrm{Mn}^{2+}-\mathrm{O}$ pairs. In such a system, the frequency of the shorter $\mathrm{Mn}^{4+}-\mathrm{O}$ pair dominates the EXAFS spectrum (Fig. 16a) and, therefore, the RSF peak for the composite Mn valency spectrum appears at the same distance as that for the pure $\mathrm{Mn}^{4+}$ spectrum, but with a lower amplitude (Fig. 16b).

\section{General Discussion}

\section{Ability of the trial-and-error XRD modeling approach to determine the structure of} turbostratic compounds. The ability of the trial-and-error approach used in the present study to unravel the structure of defect-bearing compounds has been amply demonstrated in recent studies of different birnessite varieties with an enhanced 3D ordering (Manceau et al. 1997; Drits et al. 1998a; Lanson et al. 2000, 2002a, b; Gaillot et al. 2003, 2004). Based on the above fits to the experimental data and the subsequent sensitivity analysis, it is clear that this trial-and-error approach can also be applied to build meaningful structure models for extremely defective (turbostratic stacking $-100 \%$ of random stacking faults) layered compounds. The symmetry and cation occupancy of the octahedral layer, and to some extent the amounts and positions of interlayer species, were well constrained. Specifically, it was possible to assess the presence and the number of interlayer Mn cations associated with vacant layer sites, and to determine their position with a reasonable precision (e.g., Figs. 3c and 7). The position and, to a lesser extent, the amount of "light" interlayer species, such as 
$553 \mathrm{Na}^{+}$and $\mathrm{H}_{2} \mathrm{O}$ molecules, were also obtained by this approach (e.g., Figs. 3a and 5). Our

554 modeling procedure also provided estimates of the CSD sizes in the ab plane for these 555 compounds (e.g., Figs. 3a and 6).

556 The high sensitivity of XRD profiles to the structure of highly defective phyllomanganates 557 contrasts with the limited effect reported previously for other layered compounds having a 558 turbostratic stacking, such as smectites. For example, Manceau et al. (2000a,b) used a similar 559 modeling approach to determine average cation occupancy in nontronite for which the layer 560 and interlayer structures were reasonably well known, a few parameters being left to refine. 561 For this purpose these authors used the relative intensities of 02,11 and 20,13 bands because 562 no modulations were observed for the two diffraction bands. For turbostratic layer 563 compounds, calculated XRD patterns hold information only on the structure of the layer, 564 including interlayer species, and give an estimate of the lateral extension of these layers.

565 However, no information is provided on the layer stacking mode, which is assumed to be 566 totally random. In the present case, modulations of the two $h k l$ bands, and especially of the 56720,11 band, were observed and successfully reproduced by computation assuming a 568 turbostratic stacking. As the position and profile of the bands depend on the amount and 569 atomic coordinates of both layer and interlayer species, they may be used for structural 570 chemistry determination. Similar modulations can result from the partial ordering of the layer 571 stacking (e.g., Ben Brahim et al. 1983; Ben Brahim et al. 1984; Drits \& Tchoubar 1990; Viani 572 et al. 2002). Special attention should thus be paid to the structural interpretation of these 573 modulations, and, in this respect, verifying the structural XRD model with independent data 574 from another structural technique, such as EXAFS spectroscopy, is always warranted.

576 Particle size considerations. The small coherent scattering dimensions obtained from XRD 577 simulations provided estimates for the size of the diffracting crystallites in the nanometer 
range. The implications of this small particle size include the exposure at the surface of a large proportion of the total structure. Therefore, edge surface sites, which contain unsaturated singly- and doubly-coordinated oxygen groups (Fig. 13), are expected to hold a relatively high proportion of the total particle charge and thus contribute palpably to ion sorption capacity. Other implications of small particle size may be relevant not only to reactivity studies, but also to structural characterization using wet-chemistry and spectroscopic techniques, such as those employed by Villalobos et al. (2003). For example, the molar ratio, $[\mathrm{Mn}(\mathrm{IV})+$ vacancies $] / \mathrm{O}$ is no longer expected to be 0.5 , as in infinitely large octahedral layers. The total charge will depend on both the vacancy content and the number of unsaturated oxygen bonds at the edges of the particles. Small particle size in the radial direction has the potential to create "border effects" that may influence characterization based on spectroscopic techniques that have been calibrated using samples having much larger particle size.

Comparisons between Mn oxides studied. Complementary information obtained from simulations of XRD patterns and Mn K-edge EXAFS spectra has led to more accurate determination of the structures of the biogenic Mn oxide and its two synthetic analogs investigated by Villalobos et al. (2003). Hexagonal layer symmetry was established for all three Mn oxides studied, with differences occurring mainly in the number of layer vacancies, in the cation interlayer content, and in particle size (coherent scattering domain radial dimensions and number of randomly stacked sheets per crystallite). The uncleaned sample of the biogenic Mn oxide seems to be structurally related to synthetic $\mathrm{HBi}$, including similar vacancy contents and the presence of low-valency interlayer Mn in TC configuration. However, the biogenic phase's octahedral layer is composed of tetravalent Mn only, in contrast to $\mathrm{HBi}$, but in close similarity with $\delta-\mathrm{MnO}_{2}$ and acid birnessite. Thus, the layer charge originates only from the presence of vacant layer sites. Another characteristic of the 
603 biogenic oxide is the presence of $\mathrm{Mn}^{2+}$ in the interlayer, whereas $\mathrm{HBi}$ has $\mathrm{Mn}^{3+}$, and $\delta-\mathrm{MnO}_{2}$ 604 and acid birnessite have no $\mathrm{Mn}^{2+}$. This $\mathrm{Mn}^{2+}$ is most likely a remnant of unoxidized $\mathrm{Mn}^{2+}$ 605 added to the system initially. A recent X-ray absorption study of the oxidation product of a 606 Leptothrix bacterium (Jurgensen et al. 2004) detected both $\mathrm{Mn}^{2+}$ and $\mathrm{Mn}^{3+}$ in the birnessite607 like biogenic oxide, suggesting that $\mathrm{Mn}^{3+}$ may be a structural component of certain biogenic 608 oxides. In yet another study on biogenic oxides, $\mathrm{Mn}^{3+}$ was detected by Scanning 609 Transmission X-ray Microscopy (STXM) (Pecher et al. 2003; Toner et al. 2004), but this 610 species was assigned an intermediate role in the bacterial oxidation process to $\mathrm{Mn}^{4+}$.

\section{Acknowledgments}

614 The first author would like to thank Philip N. Ross (Materials Science Divison, Lawrence 615 Berkeley National Laboratory) for use of a TGA-DTA apparatus, and John Bargar for 616 facilitating EXAFS measurements and providing technical assistance at the beamline. The 617 third author expresses gratitude to the Division of Ecosystem Sciences, University of 618 California at Berkeley, for its hospitality during a sabbatical leave visit. This research was 619 funded in part (M.V., B.T., G.S.) by the National Science Foundation, Collaborative Research 620 Activities in Environmental Molecular Science (CRAEMS) program (CHE-0089208) and in 621 part (A. M.) by a LDRD grant through the Advanced Light Source, Lawrence Berkeley 622 National Laboratory. SSRL is a national user facility operated on behalf of the U.S. DOE, 623 Office of Basic Energy Sciences.

\section{References cited}

627 Bartlett, R.J. and James, B.R. (1993) Redox chemistry of soils. Advances in Agronomy, 
629 Ben Brahim, J., Besson, G., and Tchoubar, C. (1983) Layer succession and water 630 molecules arrangement in a homogeneous two-water layer Na-smectite. 5th Meeting of 631 the European Clay Groups, p. 65-75, Prague.

632 Ben Brahim, J., Besson, G., and Tchoubar, C. (1984) Etude des profils des bandes de 633 diffraction $\mathrm{X}$ d'une beidellite-Na hydratée à deux couches d'eau. Détermination du 634 mode d'empilement des feuillets et des sites occupés par l'eau. Journal of Applied 635 Crystallography, 17, 179-188.

636 Bilinski, H., Giovanoli, R., Usui, A., and Hanzel, D. (2002). Characterization of Mn 637 oxides in cemented streambed crusts from Pinal Creek, Arizona, U.S.A., and in hot638 spring deposits from Yuno-Taki Falls, Hokkaido, Japan. American Mineralogist, 87, $639 \quad 580-591$.

640 Brindley, G.W. and Brown, G. (1980). Crystal Structures of Clay Minerals and their X-ray 641 Identification. Mineralogical Society, London.

642 Catts, J.G. and Langmuir, D. (1986). Adsorption of $\mathrm{Cu}, \mathrm{Pb}$, and $\mathrm{Zn}$ by delta-MnO2:

643 applicability of the site binding-surface complexation model. Applied Geochemistry, 1, $644 \quad 255-264$.

645 Ching, S., Krukowska, K. S., and Suib, S. L. (1999) A new synthetic route to todorokite646 type manganese oxides. Inorganica Chimica Acta 294(2), 123-132.

647 Chukhrov, F.V., Sakharov, B.A, Gorshkov, A.I., Drits, V.A., and Dikov, Y.P. (1985)

648 Crystal structure of birnessite from the Pacific Ocean. International Geology Review, $649 \quad 27,1082-1088$. 
650 Chukhrov, F.V., Gorshkov, A.I., and Drits, V.A. (1989) Supergenic manganese hydrous 651 oxides, Nauka, Moscow, 208 pp.

652 Drits, V.A. and Tchoubar, C. (1990) X-ray diffraction by disordered lamellar structures:

653 Theory and applications to microdivided silicates and carbons. Springer-Verlag, Berlin, $654 \quad 371 \mathrm{pp}$.

655 Drits, V.A., Silvester, E., Gorshkov, A.I., and Manceau, A. (1997) Structure of synthetic 656 monoclinic Na-rich birnessite and hexagonal birnessite: I. Results from X-ray 657 diffraction and selected-area electron diffraction. American Mineralogist, 82, 946-961.

658 Drits, V.A., Lanson, B., Gorshkov, A.I., and Manceau, A. (1998a) Substructure and 659 superstructure of four-layer Ca-exchanged birnessite. American Mineralogist, 83, 97$660 \quad 118$.

661 Drits, V.A., Eberl, D.D., and Srodon, J. (1998b) XRD measurement of mean thickness, 662 thickness distribution and strain for illite and illite-smectite crystallites by the Bertaut663 Warren-Averbach technique. Clays and Clay Minerals, 46, 38-50.

664 Feng, Q., Yokota, Y., Makita, Y., Yanagisawa, K., and Yamasaki, N. (2001) Synthesis of 665 tunnel manganese oxides from layered manganese oxide by hydrothermal soft 666 chemical process with $\mathrm{Rb}+$ as template. High Pressure Research, 20 (1-6) Special Iss. 667 SI, 33-38.

668 Friedl, G., Wehrli, B., and Manceau, A. (1997) Solid phases in the cycling of manganese 669 in eutrophic lakes: New insights from EXAFS spectroscopy. Geochimica et $670 \quad$ Cosmochimica Acta, 61, 275-290.

671 Gaillot, A.-C., Flot, D., Drits, V.A., Manceau, A., Burghammer, M., and Lanson, B. 
672

673

674

675

676

677

678

679

680

681

682

683

684

685

686

687

688

689

690

691

692

693

(2003) Structure of K-rich birnessite obtained by high-temperature decomposition of $\mathrm{KMnO}$. Part 1. Two-layer polytype from $800^{\circ} \mathrm{C}$ experiments. Chemistry of Materials, $15,4666-4678$.

Gaillot, A.-C., Drits, V.A., Plançon, A., and Lanson, B. (2004) Structure of K-rich birnessite obtained by high-temperature decomposition of KMnO4. Part 2. Phase and structural heterogeneities. Chemistry of Materials, 16, 1890-1905.

Ghiorse, W.C. and Ehrlich, H.L. (1992) Microbial biomineralization of iron and manganese. in H.C.W. Skinner and R.W. Fitzpatrick, Eds., Biomineralization Processes. Iron, Manganeso, Catena supplement 21.pp. 75-99, Cremlingen-Destedt, Germany.

Golden, D.C., Chen, C.C., and Dixon, J.B. (1987) Transformation of birnessite to buserite, todorokite, and manganite under mild hydrothermal treatment. Clays and Clay Minerals, 35, 271-280.

Gorshkov, A.I., Drits, V.A., Putilita, V.S., Pokrovskaya, E.V., and Sivtsov, A.V. (1992) Natural and synthetic birnessites. Lithology and Raw Materials, 6, 67-81 (in Russian).

Harvey, J.W. and Fuller, C.C. (1998) Effect of enhanced manganese oxidation in the hyporheic zone on basin-scale geochemical mass balance. Water Resources Research, $34,623-636$.

Holland, K.L. and Walker, J.R. (1996) Crystal structure modelling of a highly disordered potassium birnessite. Clays and Clay Minerals, 44, 744-748.

Howard, S.A. and Preston, K.D. (1989) Profile fitting of powder diffraction patterns. In D.L. Bish, and J.E. Post, Eds. Modern Powder Diffraction, 20, p. 217-275. 
695 Jurgensen, A., Widmeyer, J.R., Gordon, R.A., Bendell-Young, L.I., Moore, M.M., and 696 Crozier, E.D. (2004) The structure of the manganese oxide on the sheath of the bacterium Leptothrix discophora: An XAFS study. American Mineralogist, 89, 1110-

Kay, J.T., Conklin, M.H., Fuller, C.C., and O'Day, P.A. (2001) Processes of nickel and cobalt uptake by a manganese oxide forming sediment in Pinal Creek, Globe Mining District, Arizona. Environmental Science and Technology, 35, 4719-4725.

Lanson, B., Drits, V.A., Silvester, E., and Manceau, A. (2000) Structure of H-exchanged 703 hexagonal birnessite and its mechanism of formation from Na-rich monoclinic buserite at low pH. American Mineralogist, 85, 826-838.

Lanson, B., Drits, V.A., Feng, Q., and Manceau, A. (2002a) Structure of synthetic Nabirnessite: Evidence for a triclinic one-layer unit cell. American Mineralogist, 87, $1662-1671$.

Lanson, B., Drits, V.A., Gaillot, A.-C., Silvester, E., Plancon, A., and Manceau, A. (2002b) Structure of heavy-metal sorbed birnessite: Part 1. Results from X-ray diffraction. American Mineralogist, 87, 1631-1645.

711 Luo, J. and Suib, S.L. (1997) Preparative parameters, magnesium effects, and anion

712 effects in the crystallization of birnessites. Journal of Physical Chemistry B, 101, $713 \quad 10403-10413$.

714 Luo, J., Zhang, Q. H., Huang, A. M., Giraldo, O., and Suib, S. L. (1999) Double-aging 715 method for preparation of stabilized Na-buserite and transformations to todorokites 
incorporated with various metals. Inorganic Chemistry, 38, 6106-6113.

717 Luo, J., Zhang, Q., and Suib, S.L. (2000) Mechanistic and kinetic studies of crystallization 718 of birnessite. Inorganic Chemistry, 39, 741-747.

719 Manceau, A. and Combes, J.M. (1988) Structure of Mn and Fe oxides and oxyhydroxides $720-$ a topological approach by EXAFS. Physics and Chemistry of Minerals, 15, 283-295.

721 Manceau, A., Gorshkov, A.I., and Drits, V.A.(1992) Structural Chemistry of Mn, Fe, Co, 722 and Ni in Mn hydrous oxides. II. Information from EXAFS spectroscopy, electron and 723 X-ray diffraction. American Mineralogist, 77, 1144-1157.

724 Manceau, A., Drits, V. A., Silvester, E., Bartoli, C., and Lanson, B. (1997) Structural 725 mechanism of $\mathrm{Co}(\mathrm{II})$ oxidation by the phyllomanganate, Na-buserite. American $726 \quad$ Mineralogist, 82, 1150-1175.

727 Manceau, A., Chateigner, D., and Gates, W.P. (1998) Polarized EXAFS, distance-valence 728 least-squares modeling (DVLS), and quantitative texture analysis approaches to the 729 structural refinement of Garfield nontronite. Physics and chemistry of minerals, 25, $730 \quad 347-365$.

731 Manceau, A., Lanson, B., Drits, V.A., Chateigner, D., Gates, W.P., Wu, J., Huo, D.F., and 732 Stucki, J.W. (2000a) Oxidation-reduction mechanism of iron in dioctahedral smectites: 733 1. Crystal chemistry of oxidized reference nontronites. American Mineralogist, 85, $734 \quad 133-152$.

Manceau, A., Drits, V.A., Lanson, B., Chateigner, D., Gates, W.P., Wu, J., Hu,o D.F., and 736 Stucki, J.W. (2000b) Oxidation-reduction mechanism of iron in dioctahedral smectites: 2. Crystal chemistry of reduced Garfield nontronite. American Mineralogist, 85, 153- 
739

740

741

742

743

744

745

746

747

748

749

750

751

752

753

754

755

756

757

758

759

Manceau, A., Tamura, N., Celestre, R.S., MacDowell, A.A., Geoffroy, N., Sposito G., and Padmore, H.A. (2003) Molecular-scale speciation of Zn and Ni in soil ferromanganese nodules from loess soils of the Mississippi basin. Environmental Science and Technology, 37, 75-80.

Manceau, A., Marcus, M. A., Tamura, N., Proux, O., Geoffroy, N., and Lanson, B. (2004)

Natural speciation of $\mathrm{Zn}$ at the micrometer scale in a clayey soil using X-ray

fluorescence, absorption, and diffraction. Geochimica et Cosmochimica Acta, 68, $2467-2483$

Mandernack, K.W., Fogel, M.L., Tebo, B.M., and Usui, A. (1995a) Oxygen isotope analyses of chemically and microbially produced manganese oxides and manganates. Geochimica et Cosmochimica Acta, 59, 4409-4425.

Marble, J.C., Corley, T.L., Conklin, M.H., and Fuller, C.C. (1999) Environmental factors affecting oxidation of manganese in Pinal Creek, Arizona. in D.W. Moranwalp and H.T. Buxton, Eds., Water-Resources Investigation Report, pp. 173-183, US Geological Survey, West Trenton, NJ.

McKenzie, R.M. (1971) The synthesis of birnessite, cryptomelane, and some other oxides and hydroxides of manganese. Mineralalogical Magazine, 38, 493-502.

McKeown, D.A. and Post, J.E. (2001) Characterization of manganese oxide mineralogy in rock varnish and dendrites using X-ray absorption spectroscopy. American Mineralogist, 86, 701-713.

Morgan, J.J. (2000) Manganese in natural waters and earth's crust: Its availability to 
organisms. in A. Sigel and H. Sigel, Eds., Metal Ions in Biological Systems, Vol. 37, pp. 1-33, Marcel Dekker, New York..

762

Nealson, K.H., Tebo, B.M., and Rosson, R.A. (1988) Occurrence and mechanisms of 763 microbial oxidation of manganese. Advances in Applied Microbiology, 33, 279-318.

O'Day, P.A., Rehr, J.J., Zabinsky, S.I., and Brown, G.E. (1994) Extended X-ray absorption fine structure (EXAFS) analysis of disorder and multiple-scattering in complex crystalline solids. Journal of the American Chemical Society, 116, 2938-2949.

Pecher, K., McCubbery, D., Kneedler, E., Rothe, J., Bargar, J., Meigs, G., Cox, L., Nealson, K., and Tonner, B. (2003) Quantitative charge state analysis of manganese biominerals in aqueous suspension using Scanning Transmission X-ray Microscopy (STXM). Geochimica et Cosmochimica Acta 67, 1089-1098.

Plançon, A. (2002) CALCIPOW- a program for calculating the diffraction by disordered lamellar structures. Journal of Applied Crystallography, 35, 377.

Post, J.E. and Veblen, D.R. (1990) Crystal structure determinations of synthetic sodium, magnesium, and potassium birnessite using TEM and the Rietveld method. American Mineralogist, 75, 477-489.

Post, J.E., Heaney, P.J., and Hanson, J. (2002) Rietveld refinement of a triclinic structure for synthetic Na-birnessite using synchrotron powder diffraction data. Powder Diffraction, 17, 218-221.

Ressler, T (1998) WinXAS: a program for X-ray absorption spectroscopy data analysis under MS-Windows. Journal of Synchrotron Radiation, 5, 118-122.

Schlegel, M.L., Manceau, A., Charlet, L., Hazemann, J.L. (2001) Adsorption mechanism 
of $\mathrm{Zn}$ on hectorite as a function of time, $\mathrm{pH}$, and ionic strength. American Journal of Science, 301, 798-830.

784

785

786

787

788

789

790

791

792

793

794

795

796

797

Shen, Y. F., Zerger, R. P., Deguzman, R. N., Suib, S. L., Mccurdy, L., Potter, D. I., and Oyoung, C. L. (1993) Manganese Oxide Octahedral Molecular Sieves - Preparation, Characterization, and Applications. Science, 260, 511-515.

Silvester, E., Manceau, A., and Drits, V.A. (1997) Structure of synthetic monoclinic Narich birnessite and hexagonal birnessite: II. Results from chemical studies and EXAFS spectroscopy. American Mineralogist, 82, 962-978.

Strobel, P., Charenton, J.C., and Lenglet, M. (1987) Structural chemistry of phyllomanganates: Experimental evidence and structural models. Revue de Chimie Minérale, 24, 199-220.

Tebo, B.M. (1991) Manganese(II) oxidation in the suboxic zone of the Black Sea. DeepSea Research, 38, S883-S905.

Tebo, B.M. and He, L.M. (1999) Microbially mediated oxidative precipitation reactions. in D.L. Sparks and T.J. Grundl, Eds., Mineral-Water Interfacial Reactions Kinetics and Mechanisms, Chapter 20, pp. 393-414, American Chemical Society, Washington, D.C.

Tebo, B.M., Ghiorse, W.C., Waasbergen, L.G. van, Siering, P.L., and Caspi, R. (1997) Bacterially mediated mineral formation: Insights into manganese(II) oxidation from molecular genetic and biochemical studies. in J.F. Banfield and K.H. Nealson, Eds., Reviews in mineralogy, vol. 35, chapter 7, pp. 225-266, Mineralogical Society of America, Washington D.C.

Thackeray, M.M., de Kock, A., and David, W.I.F. (1993) Synthesis and structural 

characterization of defect spinels in the lithium-manganese-oxide system. Materials Research Bulletin, 28, 1041-1049.

806 Tian, Z. R., Yin, Y. G., Suib, S. L., and O'Young, C. L. (1997) Effect of $\mathrm{Mg}^{2+}$ ions on the 807 formation of todorokite type manganese oxide octahedral molecular sieves. Chemistry 808 of Materials, 9, 1126-1133

809 Tipping, E., Thompson, D.W., and Davison, W. (1984) Oxidation products of Mn(II) in $810 \quad$ lake waters. Chemical Geology, 44, 359-383.

811 Toner, B., Fakra, S., Villalobos, M., Warwick, T., and Sposito, G. (2004) Spatially

812 resolved characterization of biogenic manganese oxide production within the biofilm 813 of Pseudomonas putida strain MnB1. Applied and Environmental Microbiology (in 814 press).

815 Viani, A., Gualtieri, A.F., and Artioli, G. (2002) The nature of disorder in montmorillonite 816 by simulation of X-ray diffraction patterns. American Mineralogist, 87, 966-975.

817 Villalobos, M., Toner, B., Bargar, J., and Sposito, G. (2003) Characterization of the Mn 818 oxide produced by Pseudomonas putida strain MnB1. Geochimica et Cosmochimica $819 \quad$ Acta, 67, 2649-2662.

820 Wadsley, A.D. (1955) The crystal structure of chalcophanite, $\mathrm{ZnMn}_{3} \mathrm{O}_{7} \cdot 3 \mathrm{H}_{2} \mathrm{O}$, Acta $821 \quad$ Crystallographica, 8, 1165-1172.

822 Wehrli, B., Friedl, G., and Manceau, A. (1995) Reaction rates and products of manganese 823 oxidation at the sediment-water interface. in Aquatic Chemistry. In C.P. Huang, 824 C.O'Melia and J.J. Morgan, Eds., Advances in Chemistry Series 244, p. 111-134, 825 American Chemical Society, Washington D.C. 
Zabinsky, S.I., Rehr, J.J., Ankudinov, A., Albers, R.C., and Eller, M.J. (1995) Multiple scattering calculations of X-ray absorption spectra, Physical Reviews, 52, 2995-3009.

\section{FIGURES}

Fig. 1. Experimental XRD patterns of the Mn oxide samples. (a) acid birnessite, (b) $\delta$ $\mathrm{MnO}_{2}$, (c) biogenic oxide with cell material, (d) cell material without the biogenic oxide.

Fig. 2. Comparison between experimental ('+' symbols) and calculated (solid line) XRD patterns for the various Mn oxide samples. Structural parameters used for calculations are listed in Tables 2 and 3. Calculations are limited to the $00 \mathrm{l}$ reflections occurring below $35^{\circ} 2 \theta$ $\mathrm{CuK} \alpha$. (a) acid birnessite, (b) $\delta-\mathrm{MnO}_{2}$, (c) biogenic oxide with cell material. The lower gray trace in $(c)$ is the experimental XRD pattern for cell material without the biogenic oxide.

Fig. 3. Comparison between experimental and calculated XRD patterns for the various Mn oxide samples. Patterns as for Figure 2. Structural parameters used for calculations are listed in Tables 2 and 3. Calculations are performed for the 20,11 and for the 02,31 bands (maxima at $\sim 37$ and $66^{\circ} 2 \theta \mathrm{CuK} \alpha$, respectively). (a) $\delta-\mathrm{MnO}_{2}$, (b) acid birnessite, (c) biogenic oxide.

Fig. 4. Structure model for the various Mn oxide samples. (a) Projection on the ab plane. The upper surface of the layer is shown as light shaded triangles. $\mathrm{O}_{\text {layer }}$ atoms of this upper surface are shown as solid circles, whereas $\mathrm{Mn}_{\text {layer }}$ atoms are not shown. Large open circles 
851

852

853

854

855

856

857

858

859

860

861

862

863

864

865

866

867

868

869

870

871

872 Fig. 6. Comparison between experimental and calculated XRD patterns for $\delta-\mathrm{MnO}_{2}$.

873 Patterns as for Figure 2. Structural parameters used for calculations are listed in Tables 2 and 874 3a. Calculations are performed for the $20 l, 11 l$ and for the $02 l, 31 l$ sets of reflections (maxima 875

represent $\mathrm{Na}^{+}$cations and $\mathrm{H}_{2} \mathrm{O}$ molecules in $\delta-\mathrm{MnO}_{2}[(0.225,0,0.5)-$ Position O3]. $\mathrm{K}$ represents the position of interlayer $\mathrm{K}^{+}$cations in the acid birnessite sample. Positions labeled Alt.n $(n=1,2,3)$ represent test positions to assess the sensitivity of calculated XRD patterns to the position of interlayer species. The dashed triangle outlines the upper surface of the $\mathrm{Mn}_{\text {interlayer }}$ coordination octahedron which is defined by three $\mathrm{H}_{2} \mathrm{O}_{\text {interlayer }}$ (small open circles).

(b) Projection along the $\mathbf{b}$ axis. Open and solid symbols indicate atoms at $y=0$ and $y= \pm 1 / 2$, respectively. Large circles represent $\mathrm{O}_{\text {layer }}$ atoms, small circles represent $\mathrm{Mn}$ atoms. The solid squares represents a vacant layer site. The dashed line outlines the $\mathrm{Mn}_{\text {interlayer }}$ coordination octahedron which is defined by $\mathrm{O}_{\text {layer }}$ and $\mathrm{H}_{2} \mathrm{O}_{\text {interlayer. }}$.

Fig. 5. Comparison between experimental and calculated XRD patterns for $\delta-\mathrm{MnO}_{2}$.

Patterns as for Figure 2. Structural parameters used for calculations are listed in Tables 2 and 3a. Calculations are performed for the $20 l, 11 l$ and for the $02 l, 31 l$ sets of reflections (maxima at $\sim 37$ and $66^{\circ} 2 \theta \mathrm{CuK} \alpha$, respectively). (a) Interlayer $\mathrm{Na}^{+}$cations and $\mathrm{H}_{2} \mathrm{O}$ molecules are located above or below layer octahedra [position $(0.0,0.0,0.5)-$ Alt. 1 in Fig. 4] rather than in the optimum $\mathrm{O} 3$ position $(0.225,0.0,0.5)$ (Fig. 3a). (b) Interlayer $\mathrm{Na}^{+}$cations and $\mathrm{H}_{2} \mathrm{O}$ molecules are located in $(0.333,0.0,0.5)$ (position Alt. 2 in Fig. 4$)$ rather than in the optimum $\mathrm{O} 3$ position $(0.225,0.0,0.5)$. (c) Interlayer $\mathrm{Na}^{+}$cations and $\mathrm{H}_{2} \mathrm{O}$ molecules are located above/below the tridentate cavities at the layer surface [Position "Alt. 3" in Fig. 4 with coordinates $(-0.167,0.0,0.5)]$ rather than in the optimum $\mathrm{O} 3$ position $(0.225,0.0,0.5)$.

\footnotetext{
at $\sim 37$ and $66^{\circ} 2 \theta \mathrm{CuK} \alpha$, respectively). (a) Mean radial dimension of the CSD in the ab plane
} 
876 is increased from the optimum $5.8 \mathrm{~nm}$ (Fig. 3a) to $10.0 \mathrm{~nm}$. (b) Mean radial dimension of the

877 CSD in the ab plane is decreased from the optimum $5.8 \mathrm{~nm}$ to $3.0 \mathrm{~nm}$.

878

879 Fig. 7. Comparison between experimental and calculated XRD patterns for the biogenic

880 oxide. Patterns as for Figure 2. Structural parameters used for calculations are listed in

881 Tables 2 and 3c. Calculations are performed for the $20 l, 11 l$ an for the $02 l, 31 l$ sets of

882 reflections (maxima at $\sim 37$ and $66^{\circ} 2 \theta \mathrm{CuK} \alpha$, respectively). (a) Amounts of vacant layer sites

883 and of interlayer Mn cations are assumed to be 0.167 and 0.100 , as compared to the optimum

8840.167 and 0.167 values (Fig. 3c), respectively. (b) Amounts of vacant layer sites and of

885 interlayer Mn cations are assumed to be 0.100 and 0.100 , as compared to the optimum 0.167

886 and 0.167 values, respectively. (c) Interlayer Mn cations are located above/below the

887 tridentate cavities at the layer surface [Position "Alt. 3" in Fig. 4 with coordinates (-0.167,

$8880.0,0.299)]$ rather than in the optimum position $(0.0,0.0,0.299)$.

889

890 Fig. 8. (a) $\mathrm{k}^{3}$-weighted Mn K-edge EXAFS spectra of Mn oxides lacking 3D ordering and of

891 H-birnessite. (b) Magnitude of the Fourier transform (uncorrected for phase shifts).

892

893 Fig. 9. Comparison between $\mathrm{k}^{3}$-weighted Mn K-edge EXAFS spectra of (a) the cleaned

894 biogenic $\mathrm{Mn}$ oxide and $\delta-\mathrm{MnO}_{2}$, (b) the cleaned biogenic Mn oxide and acid birnessite, and

895 (c) the uncleaned biogenic Mn oxide and H-birnessite. The arrow denotes the area where the 896 biogenic oxide and H-birnessite overlap (Manceau et al. 1997).

897

898 Fig. 10. Comparison between the magnitude and imaginary part of the Fourier transforms

899 (uncorrected for phase shifts) for (a) the cleaned biogenic $\mathrm{Mn}$ oxide and $\delta-\mathrm{MnO}_{2}$, (b) the

900 cleaned biogenic Mn oxide and acid birnessite, and (c) the uncleaned biogenic Mn oxide and 
H-birnessite. The letters refer to the four different shells identified. A indicates the peak due

to $\mathrm{Mn}-\mathrm{O}(1)$ distance, $\mathrm{B}$ to the $\mathrm{Mn}-\mathrm{Mn}(1)$ distance, $\mathrm{C}$ mostly to the $\mathrm{Mn}-\mathrm{Mn}(\mathrm{tc})$ distance, and

903 D to the third Mn layer shell distance. The latter was not modeled with the single scattering

904

905

906

907

908

909

910

911

912

913

914 Fig. 13. Comparison between the EXAFS data of the cleaned and uncleaned biogenic Mn

915

916

917

918 Fig. 14. Fourier-filtered experimental EXAFS spectra of the $1.0<R+\Delta R<3.1 \AA$ region for

919 (a) H-birnessite and the uncleaned biogenic Mn oxide; and FEFF simulations for (b) H-

920 birnessite, and (c) the uncleaned biogenic Mn oxide, according to the parameters listed in 921 Table 5.

922

923 Fig. 15. EXAFS contribution of the Mn-O(1) shell for a theoretical Mn oxide composed of

$92480 \% \mathrm{Mn}^{4+}$ and $20 \% \mathrm{Mn}^{2+}$, which shows that despite the widely differing $\chi(k)$ frequencies (a) 
925 obtained, and corresponding radial structure functions (b), the dominant $\chi(k)$ function and $926 \mathrm{RSF}$ of the mixture is that of the shorter $\mathrm{Mn}^{4+}-\mathrm{O}$ distance, with amplitude reductions. 927 
Table 1. Physicochemical properties of the Mn oxides investigated

\begin{tabular}{|c|c|c|c|}
\hline Mn oxide & $\begin{array}{c}\mathrm{H}_{2} \mathrm{O} \text { content } \\
(\% \mathrm{w} / \mathrm{w}) \\
( \pm 0.02)\end{array}$ & $\begin{array}{c}\text { Average } \\
\text { Mn Oxidation } \\
\text { Number } \\
( \pm 0.02)^{\dagger}\end{array}$ & $\begin{array}{c}\text { Structural } \\
\text { Alc*/Mn } \mathrm{Mnt}_{\text {tot }} \\
(\mathrm{mol} \%)^{\dagger}\end{array}$ \\
\hline Biogenic $^{\#}$ & 10.0 & $3.90 \pm 0.05$ & $(\mathrm{pH} 8.1) 16.7 \pm 0.3$ \\
\hline Acid Birnessite & 7.5 & 3.96 & (pH 5.6) $20.4 \pm 0.8$ \\
\hline$\delta-\mathrm{MnO}_{2}$ & 15.8 & 4.02 & $(\mathrm{pH} 8.1) 25.3 \pm 0.1$ \\
\hline $\begin{array}{l}\text { Note: "From Vill } \\
\text { for "acid birnessite" an }\end{array}$ & $\begin{array}{l}\text { 1. }(2003) ;{ }^{*} \mathrm{Al} \\
\text { he others; }{ }^{\#} \mathrm{~F}\end{array}$ & $\begin{array}{l}\text { s to the alkalin } \\
\text { seudomonas pu }\end{array}$ & interion, which is $\mathrm{K}$ \\
\hline
\end{tabular}


933 Table 2. Optimum structural parameters used for the simulation of the three experimental X934 ray diffraction profiles (cf. Figs. 2, 3).

935

\begin{tabular}{cccc}
\hline Atom & $\delta-\mathrm{MnO}_{2}$ & Acid birnessite & Biogenic oxide \\
\hline $\mathrm{a}(\AA)$ & 4.916 & 4.916 & 4.916 \\
$\mathrm{~b}(\AA)$ & 2.838 & 2.838 & 7.20 \\
$d(001)(\AA)$ & 7.20 & 7.20 & 2.8 \\
Average CSD size & 2.6 & 5.8 & 85 \\
$\left(\right.$ along the $\mathbf{c}^{*}$ axis $)$ & & & \\
Average CSD size & 60 & 70 & \\
(in the ab plane) & & & \\
\hline
\end{tabular}

Note: Optimal values were determined by trial-and-error fitting of the experimental XRD patterns. $a$ and $b$ parameters were determined from the simulation of the $h k l$ bands whereas the $c$ parameter was estimated from the simulation of the 001 reflections. Coherent scattering domain (CSD) sizes along $\mathbf{c}^{*}$ are expressed as number of layers, whereas the average radius of the CSDs in the ab plane is expressed in $\AA$. The latter values have been determined to fit the 20,11 band. 
Table 3a. Optimum structural parameters used for the simulation of $\delta-\mathrm{MnO}_{2} \mathrm{X}$-ray diffraction profile (cf. Fig. 3a).

939

\begin{tabular}{|c|c|c|c|c|c|c|c|c|}
\hline Atom & $x$ & $y$ & $\zeta$ & Occ. & $x$ & $y$ & $\zeta$ & Occ. \\
\hline $\mathrm{Mn}_{\text {layer }}$ & 0 & 0 & 0 & 0.94 & - & - & - & - \\
\hline $\mathrm{O}_{\text {layer }}$ & 0.333 & 0 & 1.00 & 1.00 & -0.333 & 0 & -1.00 & 1.00 \\
\hline $\mathrm{Mn}_{\text {interlayer }}$ & - & - & - & 0.00 & - & - & - & 0.00 \\
\hline $\mathrm{H}_{2} \mathrm{O}_{\text {interlayer }}$ & - & - & - & 0.00 & - & - & - & 0.00 \\
\hline $\mathrm{Na}_{\text {interlayer }}$ & 0.225 & 0 & 3.60 & 0.04 & -0.225 & 0 & -3.60 & 0.04 \\
\hline $\mathrm{Na}_{\text {interlayer }}$ & -0.1125 & 0.3375 & 3.60 & 0.04 & -0.1125 & -0.3375 & 3.60 & 0.04 \\
\hline $\mathrm{Na}_{\text {interlayer }}$ & 0.1125 & 0.3375 & -3.60 & 0.04 & 0.1125 & -0.3375 & -3.60 & 0.04 \\
\hline $\mathrm{H}_{2} \mathrm{O}_{\text {interlayer }}$ & 0.225 & 0 & 3.60 & 0.12 & -0.225 & 0 & -3.60 & 0.12 \\
\hline $\mathrm{H}_{2} \mathrm{O}_{\text {interlayer }}$ & -0.1125 & 0.3375 & 3.60 & 0.12 & -0.1125 & -0.3375 & 3.60 & 0.12 \\
\hline $\mathrm{H}_{2} \mathrm{O}_{\text {interlayer }}$ & 0.1125 & 0.3375 & -3.60 & 0.12 & 0.1125 & -0.3375 & -3.60 & 0.12 \\
\hline
\end{tabular}

Note: Optimal values were determined by trial-and-error fitting of the experimental XRD patterns. $x$, and $y$ coordinates are expressed as fractions of the $a$ and $b$ parameters, respectively. Coordinates along the $\mathbf{c}^{*}$ axis, $\zeta$, are expressed in $\AA$ to emphasize the thickness of layer and interlayer polyhedra. Un-refined thermal $B$ factors are 0.5 for $\mathrm{Mn}_{\text {layer }}, 1.0$ for $\mathrm{O}_{\text {layer }}$ and $\mathrm{Mn}_{\text {interlayer, }}$, and 1.5 for interlayer $\mathrm{H}_{2} \mathrm{O}$ molecules associated with $\mathrm{Mn}_{\text {interlayer, }}$ and 2.0 for other interlayer species (alkali cations and $\mathrm{H}_{2} \mathrm{O}$ molecules) 
941 Table 3b. Optimum structural parameters used for the simulation of acid birnessite X-ray

942 diffraction profile (cf. Fig. 3b).

943

\begin{tabular}{|c|c|c|c|c|c|c|c|c|}
\hline Atom & $x$ & $y$ & $\zeta$ & Occ. & $x$ & $y$ & $\zeta$ & Occ. \\
\hline $\mathrm{Mn}_{\text {layer }}$ & 0 & 0 & 0 & 0.88 & - & - & - & - \\
\hline $\mathrm{O}_{\text {layer }}$ & 0.333 & 0 & 1.00 & 1.00 & -0.333 & 0 & -1.00 & 1.00 \\
\hline $\mathrm{Mn}_{\text {interlayer }}$ & 0 & 0 & 2.15 & 0.04 & 0 & 0 & -2.15 & 0.04 \\
\hline $\mathrm{H}_{2} \mathrm{O}_{\text {inter. }}$ & -0.333 & 0 & 3.35 & 0.12 & 0.333 & 0 & -3.35 & 0.12 \\
\hline $\mathrm{K}_{\text {interlayer }}$ & -0.203 & 0 & 3.60 & 0.03 & 0.203 & 0 & -3.60 & 0.03 \\
\hline $\mathrm{K}_{\text {interlayer }}$ & -0.4167 & 0.125 & 3.60 & 0.03 & -0.4167 & -0.125 & 3.60 & 0.03 \\
\hline $\mathrm{K}_{\text {interlayer }}$ & 0.4167 & 0.125 & -3.60 & 0.03 & 0.4167 & -0.125 & -3.60 & 0.03 \\
\hline $\mathrm{H}_{2} \mathrm{O}_{\text {inter. }}$ & 0.200 & 0 & 3.60 & 0.09 & -0.200 & 0 & -3.60 & 0.09 \\
\hline $\mathrm{H}_{2} \mathrm{O}_{\text {inter. }}$ & -0.100 & 0.300 & 3.60 & 0.09 & -0.100 & -0.300 & 3.60 & 0.09 \\
\hline $\mathrm{H}_{2} \mathrm{O}_{\text {inter. }}$ & 0.100 & 0.300 & -3.60 & 0.09 & 0.100 & -0.300 & -3.60 & 0.09 \\
\hline
\end{tabular}

944

945 
945 Table 3c. Optimum structural parameters used for the simulation of the biogenic oxide X-ray

946 diffraction profile (cf. Fig. 3c).

947

\begin{tabular}{ccccccccc}
\hline Atom & $x$ & $y$ & $\zeta$ & Occ. & $x$ & $y$ & $\zeta$ & Occ. \\
\hline $\mathrm{Mn}_{\text {layer }}$ & 0 & 0 & 0 & 0.833 & - & - & - & - \\
$\mathrm{O}_{\text {layer }}$ & 0.333 & 0 & 1.00 & 1.00 & -0.333 & 0 & -1.00 & 1.00 \\
$\mathrm{Mn}_{\text {interlayer }}$ & 0 & 0 & 2.15 & 0.0833 & 0 & 0 & -2.15 & 0.0833 \\
$\mathrm{H}_{2} \mathrm{O}_{\text {inter. }}$ & -0.333 & 0 & 3.35 & 0.25 & 0.333 & 0 & -3.35 & 0.25 \\
$\mathrm{Na}_{\text {interlayer }}$ & 0.225 & 0 & 3.60 & 0.04 & -0.225 & 0 & -3.60 & 0.04 \\
$\mathrm{Na}_{\text {interlayer }}$ & -0.1125 & 0.3375 & 3.60 & 0.04 & -0.1125 & -0.3375 & 3.60 & 0.04 \\
$\mathrm{Na}_{\text {interlayer }}$ & 0.1125 & 0.3375 & -3.60 & 0.04 & 0.1125 & -0.3375 & -3.60 & 0.04 \\
$\mathrm{H}_{2} \mathrm{O}_{\text {inter. }}$ & 0.225 & 0 & 3.60 & 0.12 & -0.225 & 0 & -3.60 & 0.12 \\
$\mathrm{H}_{2} \mathrm{O}_{\text {inter. }}$ & -0.1125 & 0.3375 & 3.60 & 0.12 & -0.1125 & -0.3375 & 3.60 & 0.12 \\
$\mathrm{H}_{2} \mathrm{O}_{\text {inter. }}$ & 0.1125 & 0.3375 & -3.60 & 0.12 & 0.1125 & -0.3375 & -3.60 & 0.12 \\
\hline
\end{tabular}

948

949 
949 Table 4. Typical inter-atomic distances calculated from the optimum atomic coordinates.

950

\begin{tabular}{lccc}
\hline Atomic pair & $\delta-\mathrm{MnO}_{2}$ & Acid birnessite & Biogenic oxide \\
\hline $\mathrm{Mn}_{\text {layer }}-\mathrm{O}_{\text {layer }}$ & $1.920 \AA$ & $1.920 \AA$ & $1.920 \AA$ \\
$\mathrm{Mn}_{\text {inter. }}-\mathrm{O}_{\text {layer }}$ & - & $2.00 \AA$ & $2.00 \AA$ \\
$\mathrm{Mn}_{\text {inter. }}-\mathrm{H}_{2} \mathrm{O}$ & - & $2.03 \AA$ & $2.03 \AA$ \\
$* \mathrm{Alc}_{\text {inter. }}-\mathrm{O}_{\text {layer }}$ & $2.65 \AA$ & $2.97 \AA$ & $2.65 \AA$ \\
$* \mathrm{Alc}_{\text {inter }}-\mathrm{H}_{2} \mathrm{O}$ & $2.838 \AA$ & $2.93 \times 1 / 2.99 \times 2 /$ & $2.838 \AA$ \\
& & $3.02 \times 2 \AA$ & \\
$\mathrm{H}_{2} \mathrm{O}_{\text {inter }}-\mathrm{O}_{\text {layer }}$ & $2.65 \AA$ & $2.68 \AA$ & $2.65 \AA$ \\
\hline
\end{tabular}

952 * Alc $_{\text {inter }}$ refers to the alkaline interlayer counterion, which is $\mathrm{K}^{+}$for "acid birnessite" and $\mathrm{Na}^{+}$ 953 for the others. Inter-atomic distances from interlayer species to $\mathrm{O}_{\text {layer }}$ are calculated with 954 respect to a unique layer, without adjacent layer whose actual position is unknown as a result 955 of the turbostratic stacking. 
Table 5. Optimized simulation parameters of K-edge Mn EXAFS for biogenic Mn

960 oxide and synthetic analogs.

\begin{tabular}{|c|c|c|c|c|c|c|c|c|c|c|c|c|c|}
\hline \multirow[t]{3}{*}{ Sample } & \multicolumn{13}{|c|}{ Shells ${ }^{\dagger}$} \\
\hline & \multicolumn{3}{|c|}{ Mn-O (1) } & \multicolumn{3}{|c|}{$\mathrm{Mn}-\mathrm{O}(2)^{\ddagger}$} & \multicolumn{3}{|c|}{ Mn-Mn (1) } & \multicolumn{3}{|c|}{ Mn-Mn (tc) } & \multirow[t]{2}{*}{$\Delta \mathrm{E}$} \\
\hline & $\mathrm{R}(\AA)$ & $\mathrm{N}$ & $\begin{array}{c}\sigma^{2} \\
\left(\AA^{2}\right)\end{array}$ & $\mathrm{R}(\AA)$ & $\mathrm{N}$ & $\begin{array}{c}\sigma^{2} \\
\left(\AA^{2}\right)\end{array}$ & $\mathrm{R}(\AA)$ & $\mathrm{N}$ & $\sigma^{2}\left(\AA^{2}\right)$ & $\mathrm{R}(\AA)$ & $\mathrm{N}$ & $\sigma^{2}\left(\AA^{2}\right)$ & \\
\hline$\delta-\mathrm{MnO}_{2}$ & 1.90 & 5.7 & 0.0042 & 3.49 & $6^{*}$ & 0.0167 & 2.88 & 4.3 & 0.0042 & - & - & - & 0.6 \\
\hline $\begin{array}{l}\text { Acid } \\
\text { Birnessite }\end{array}$ & 1.90 & 5.3 & 0.0038 & 3.50 & $6^{*}$ & 0.0134 & 2.88 & 4.6 & 0.0045 & - & - & - & 0.8 \\
\hline $\begin{array}{l}\mathrm{H}- \\
\text { birnessite }\end{array}$ & 1.91 & 4.5 & 0.0032 & 3.61 & $6^{*}$ & 0.0049 & 2.89 & 4.8 & $0.0051^{\#}$ & 3.49 & 2.8 & $0.0051^{\#}$ & 1.6 \\
\hline $\begin{array}{l}\text { Biogenic } \\
\text { (clean) }\end{array}$ & 1.90 & 5.1 & 0.0035 & 3.42 & $6^{*}$ & 0.0149 & 2.87 & 2.9 & 0.0033 & - & - & - & $\begin{array}{c}- \\
0.4\end{array}$ \\
\hline
\end{tabular}

Biogenic (unclean)

$\lambda-\mathrm{MnO}_{2}$ (standard)

961 Note: $^{\dagger} \mathrm{S}_{0}{ }^{2}$ values used for the amplitude normalization were 0.73 for the $\mathrm{O}(1)$ shell and 0.80 962 for the Mn shells. Typical uncertainty on Mn-O (1), Mn-Mn (1), and Mn-Mn (tc) 963interatomic distances and coordination numbers are $0.02 \AA$ and \pm 1.5 , respectively. 964 The $\mathrm{Mn}-\mathrm{O}(2)$ shell contribution is very weak and thus a high correlation occurs between 965 the optimized frequency and $\Delta \mathrm{E}$, resulting in a low precision of the predicted parameters. $966^{*}$ Fixed value in the optimization procedure.

$967^{\#} \sigma$ values for the $\mathrm{Mn}(1)$ and $\mathrm{Mn}(\mathrm{tc})$ shells were floated but kept identical. 968 







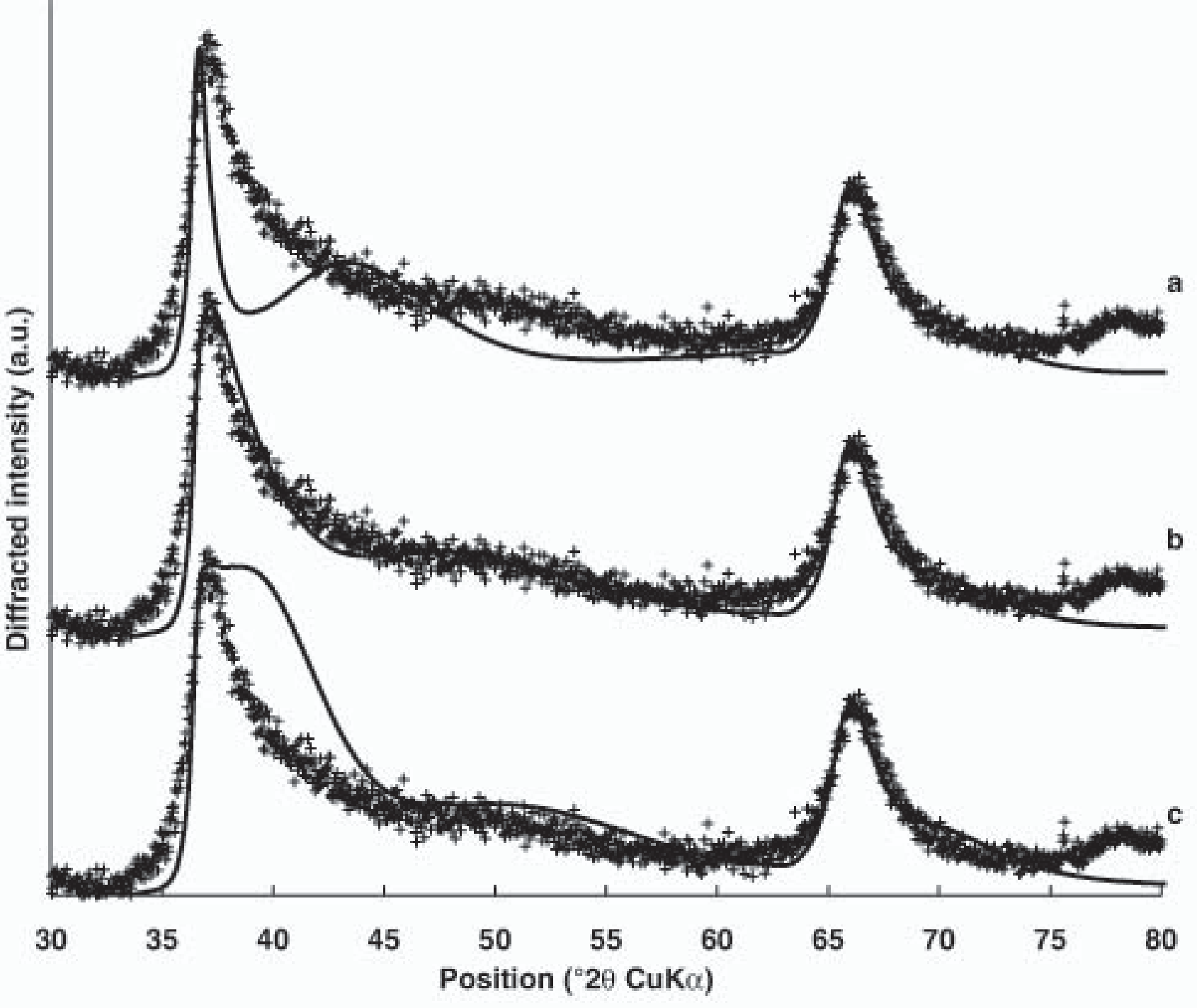




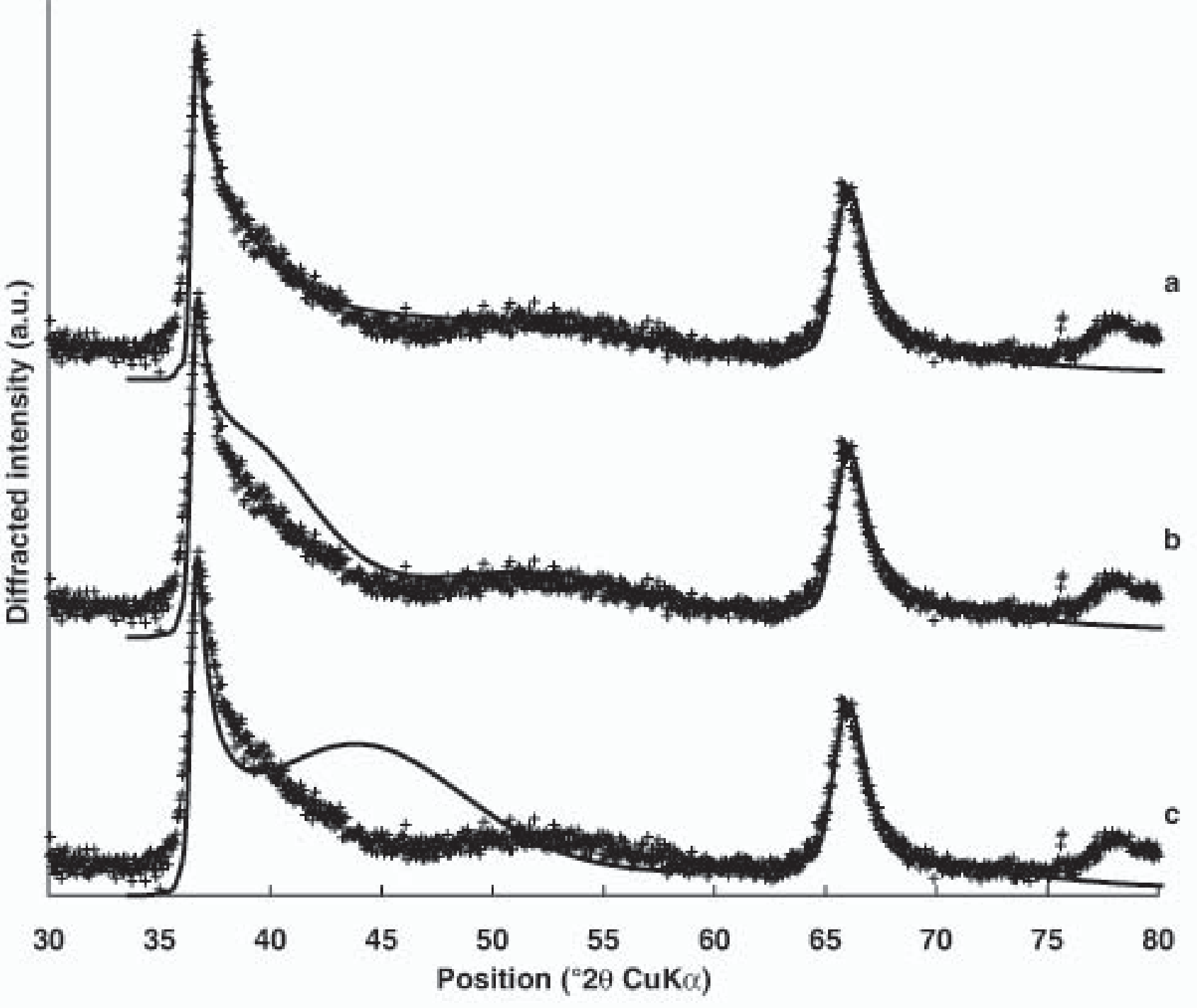



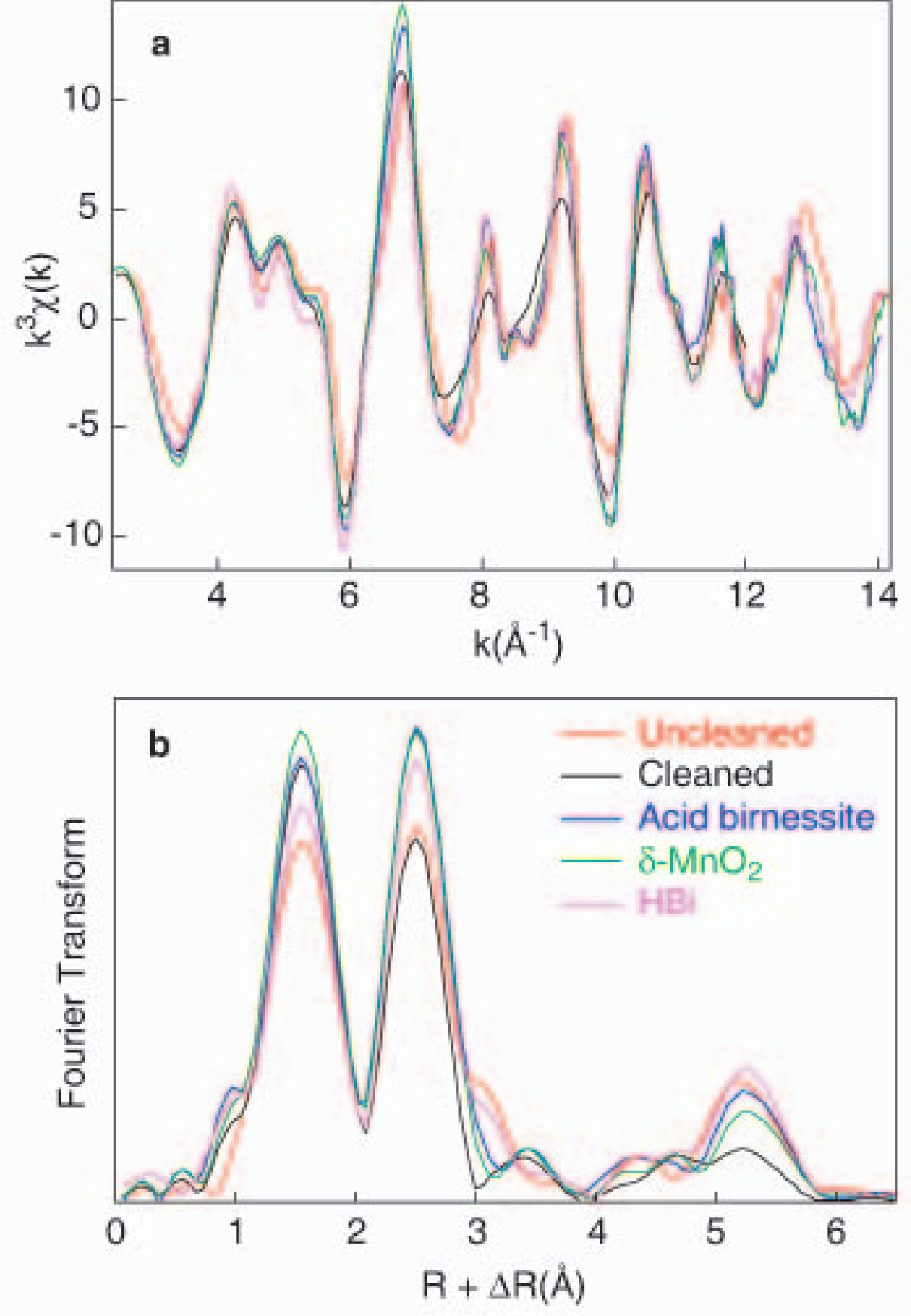


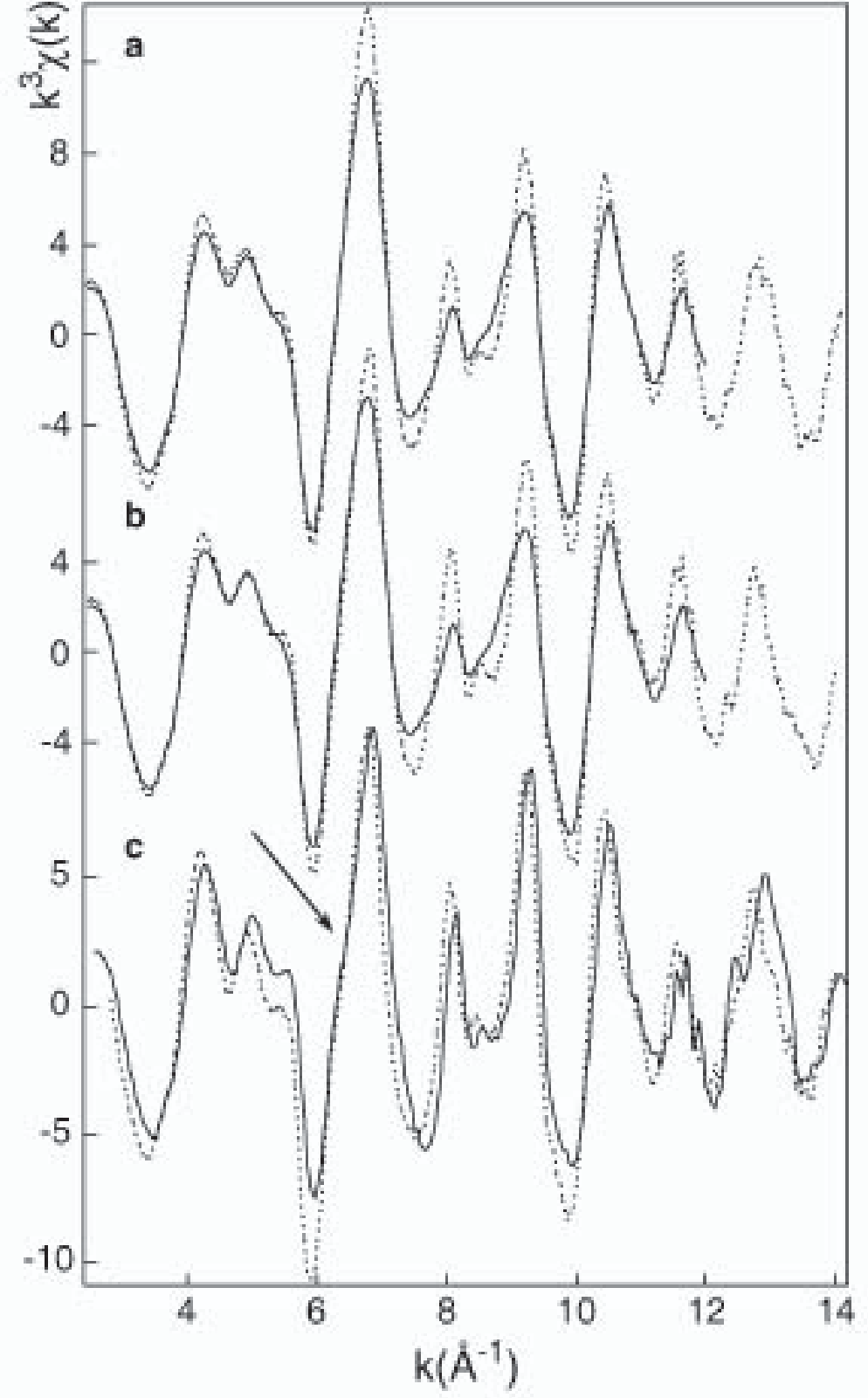




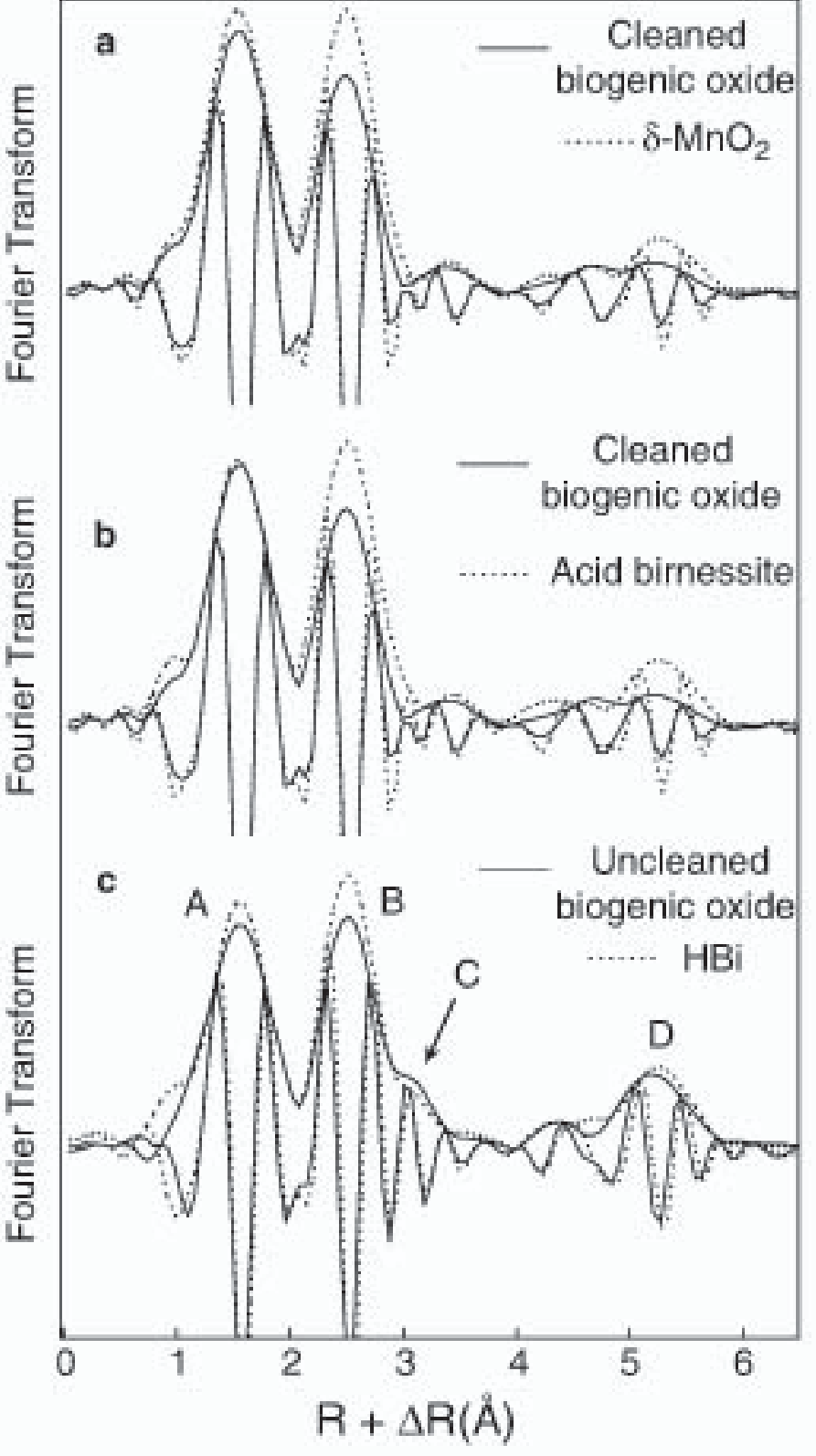



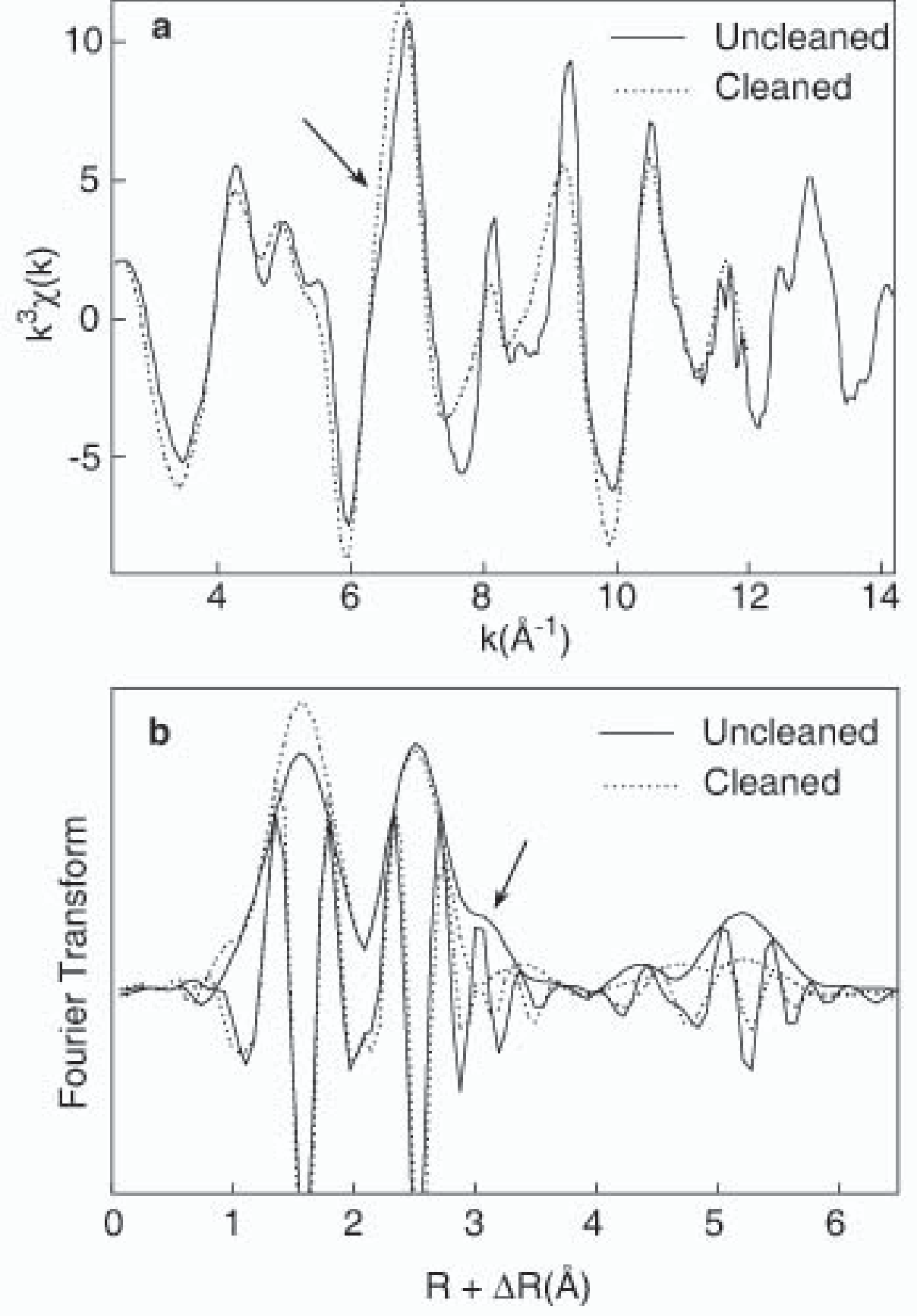

